\title{
Organic Solar Cells Performances Improvement Induced by Interface Buffer Layers
}

\author{
J. C. Bernède¹, A. Godoy², L. Cattin¹, F. R. Diaz, \\ M. Morsli ${ }^{1}$ and M. A. del Valle ${ }^{3}$ \\ ${ }^{1}$ Université de Nantes, Nantes Atlantique Universités, LAMP, EA 3825, Faculté des \\ Sciences et des Techniques, 2 rue de la Houssinière, BP 92208, Nantes, F-44000 \\ ${ }^{2}$ Facultad Ciencias de la Salud, Universidad Diego Portales. Ejército 141. Santiago de Chile \\ ${ }^{3}$ Facultatd de Quimica, PUCC, Casilla 306, Correo 22, Santiago, \\ ${ }^{1}$ France \\ ${ }^{2,3}$ Chile
}

\section{Introduction}

The energy sector has a constrained future, since increasing demand coincides with "prise de conscience" of the negative implications of fossil energy use. Global warming is finally a clear evidence of the fundamental idea of the "old" Newtonian physics: there is no action without reaction. Fundamental principle neglected by the occidental world during the last century. That is to say, we cannot continue to emit continuously carbon dioxide, nitrogen dioxide... and others pollutants produced from the burning of fossil energies into our environment without suffering the consequences. Some environmental scientists have highlighted this problem for some time [Lüthi et al., Nature, 2008], but only now are some governments giving the issue the attention that it deserves. Man-made climate change is one of the greatest threats our world faces. Renewable energies issued from our natural environment, such as wind power, solar thermal, photovoltaic, geothermal heat, marine and hydro power..., can help reduce our dependence on fossil energies. The present review is dedicated to photovoltaic energy and more precisely to some specific photovoltaic devices based on organic materials.

Photovoltaic cells belong to the family of the optoelectronic devices. As evidenced by their denomination, such devices use the optical and electronic transport properties of different materials to either produce electromagnetic radiation (light emitting diodes) or to generate electricity (photovoltaic cells -PV cells). Photovoltaic cells also called solar cells are used to generate electrical power. A PV cell is a device based on the photoconductive properties of semiconductor materials -for carriers generation- coupled with the ability of these semiconductors to form junctions -for carriers separation. The photoconductivity is the process in which electromagnetic energy is absorbed by a material and converted to excitation energy of electric charge carriers so that the material becomes quite conductor. When irradiated by a light, PV cells produce electrical energy across any connected external load. When irradiated without load a PV cell produces a maximum photogenerated voltage $\mathrm{V}_{\mathrm{oc}}$, the open-circuit voltage. When shorted, the PV cell produces the maximum short circuit 
current $\mathrm{I}_{\mathrm{sc}}$. When connected to a load the power output of the cell is given by the voltage current product $\mathrm{VxI}$. The maximal power generated possible is $\mathrm{V}_{\mathrm{oc}} \mathrm{xI}_{\mathrm{sc}}$. In fact the maximum power a PV cell is able generating depends on the dark I-V characteristics, that is to say on the diode properties of the junction constituting the device. When the load value is optimised, the maximum power provided by the cell is $\mathrm{Pm}=\mathrm{V}_{\mathrm{m}} \times \mathrm{I}_{\mathrm{m}}$. A figure of merit called the fill factor, FF, for the PV cells is given by:

$$
\mathrm{FF}=\mathrm{V}_{\mathrm{m}} \times \mathrm{I}_{\mathrm{m}} / \mathrm{V}_{\mathrm{oc}} \times \mathrm{I}_{\mathrm{sc}}(1) .
$$

Up to now, inorganic materials are used in photovoltaic cells. Crystalline, polycrystalline and amorphous silicon represent more than $95 \%$ of the world production, while CdTe and $\mathrm{Cu}(\mathrm{In}, \mathrm{Ga}) \mathrm{Se}_{2}$ (CIGS) are now emerging in the market. Crystalline (or polycrystalline) devices allow achieving efficiencies up to $25 \%$. However, efficient crystalline (or polycrystalline) devices are difficult and expensive to produce and the pay-back time of such modules is around three years. Traditionally, optoelectronic devices were grown using inorganic compounds. However, some years ago, research devoted to organic light emitting diodes (OLEDs) encounter an unexpected success [Jain et al., Semiconductors and semimetals, 2007] and they are now available on the market. Moreover it has been shown that the quantum efficiency of the electron transfer from an excited polymer to fullerene $\left(\mathrm{C}_{60}\right)$ is very high [Xiong Gong et al. Sciences, 1992]. So, since the pioneering work of Tang [Tang, Appl. Phys. Lett., 1986] the interest devoted to organic solar cells has been raising very fast, which has undergone a gradual evolution of the energy conversion efficiency, $\eta$, from less than $1 \%$ to more than 5\% [Kim et al., Sciences, 2007, Xue et al., J. Appl. Phys., 2005]. These significant progresses demonstrate that organic solar cells are a potential avenue to low cost next generation solar cells. However, some efforts are still necessary to improve the cell efficiency and lifetime. To overcome the quite narrow absorbance domain of the organic photoactive layer, several approaches such as low band gap organic material, incorporation of metal nanostructures, use of inorganic optical spacer between the active layer and the electrode can be used. It is also well known that carriers exchange at interfaces organic material/electrode can greatly influence device performance. In the present review, based on our recent studies, we will discuss more specifically possible device improvement through interface optimisation. The plan of the manuscript is as follow, after recalling some generality on organic solar cells and the classical interface theory in semiconductors, impact of electrode/organic interface properties on cells performances will be discussed using different published results, and more specifically studied from our last results. All the results will be critically discussed in the context of how to improve the fundamental understanding of interface behavior to enhance solar cells performance.

\section{A short comparison with organic light emitting diodes}

As said above, the development of efficient organic displays based on organic light emitting devices (OLEDs) has shown that organic electronic components are viable. Those displays are now developed using low cost technology and these new technologies development for OLED can be tested for PV solar cells realisation [Bernède et al., Current Trends in polymer Sciences, 2001]. Basically the underlying principle of a photovoltaic solar cell is the reverse of the principle of OLED Figure 1. 

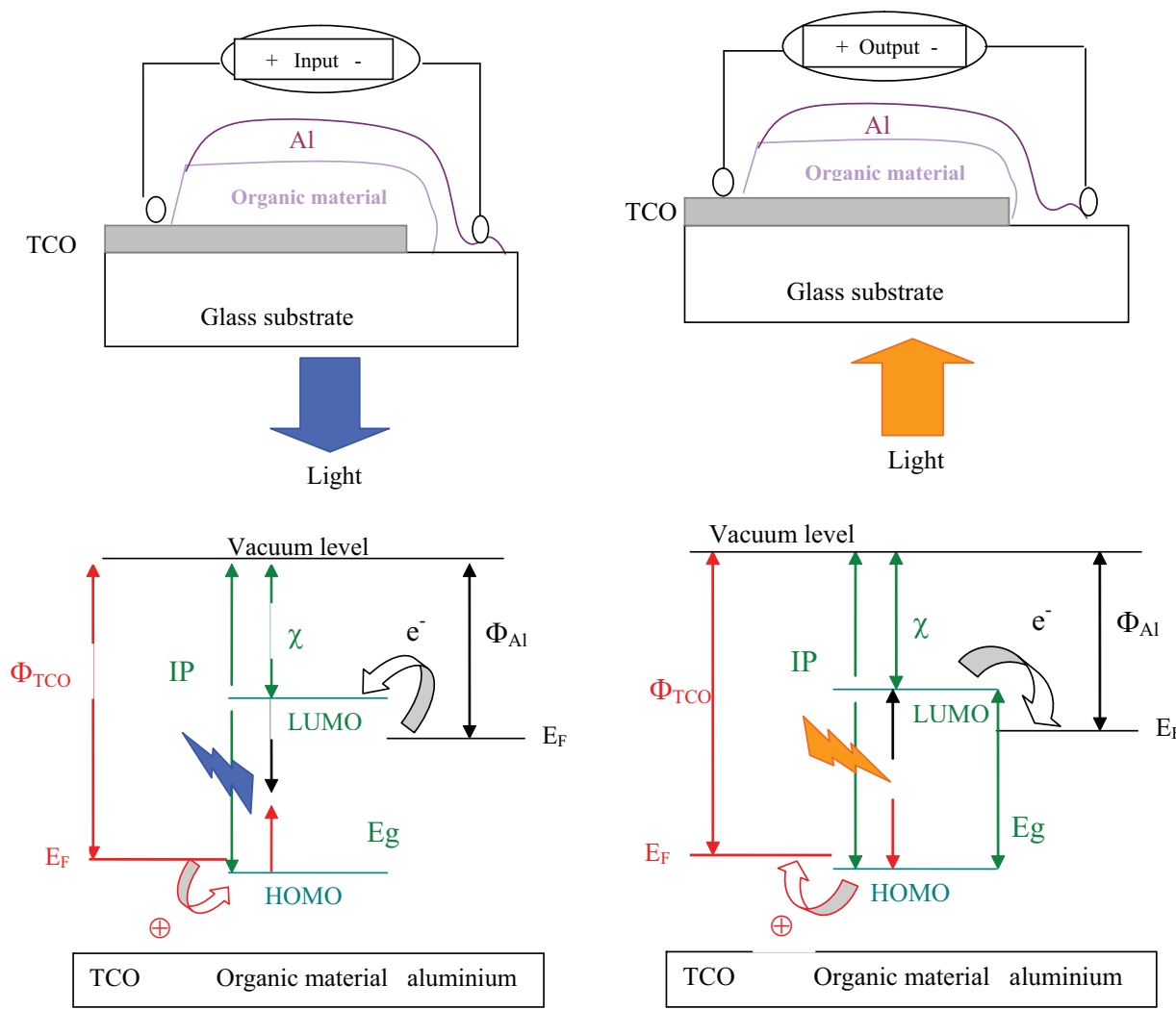

Fig. 1. Principle of an OLED (left) and a solar cell (right) (Band scheme without contact)

In OLED, electrons are injected at the low work function electrode (cathode), while holes are injected at the high work function electrode (anode). At some point in the organic, the electron and hole meet and recombine with light emission. The reverse happens in a PV cell, when light is absorbed an exciton forms. After exciton dissociation, the electron must reach the low work function electrode and the hole the high work function electrode.

In fact, when the organic material is put into contact with electrode, the shape of the band scheme depends on the conductance of the organic material Figure 2.

When the cells are short circuited, the Fermi levels of the electrodes align. If the organic is an insulator, the field profile changes linearly through the cell (fig. 2b). If the organic is a p-type semiconductor a depletion layer forms on the side of the metal with small work function, we have Schottky contact (fig. 2c). Usually the former scheme is used in OLEDs, the organic films used being quite insulating and the latter scheme is often used in solar cells, the organic active layers being semiconducting.

Almost all organic optoelectronic devices have a planar layered structure, where the organic active layer(s) is (are) sandwiched between two different electrodes. One of them must be 
transparent. A transparent conductive oxide (TCO) is used, usually indium tin oxide (ITO) because it allows achieving better results. The other electrode is very often aluminium, even if calcium has a better work function, because $\mathrm{Al}$ is stable in air while $\mathrm{Ca}$ is not. From the above comparison it can be concluded that a device which exhibits high electro-luminescent properties will be a poor solar cell and vice versa. However in both devices families the properties of the contact electrode/organic material are determinant to the efficiency of the devices, and the progress in that field for one device family is very helpful for the other family.

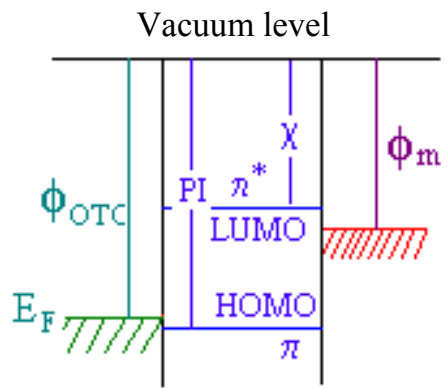

a: before contact

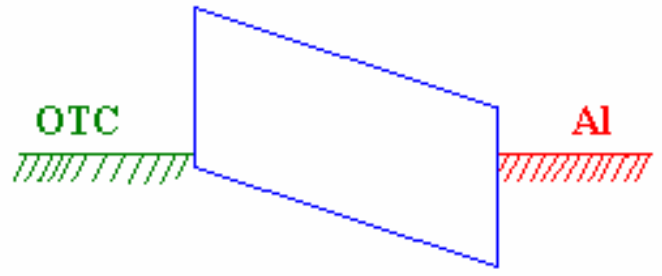

b: after contact, with an insulating organic material

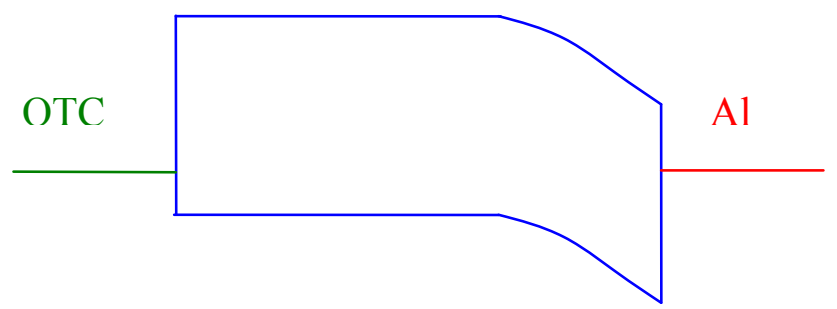

c: after contact, with an organic p-type semiconductor material

Fig. 2. Band scheme of $\mathrm{TCO} /$ organic/ $\mathrm{Al}$ structure

\section{Different organic solar cells families}

Organic semiconductors, such as macromolecules dyes, dendrimers, oligomers, polymers..., are all based on conjugated $\pi$ electrons. Conjugated systems are based on an alternation between single and double bonds. The main property related to this conjugation is that $\pi$ electrons are more mobile than $\sigma$ electrons. Therefore the $\pi$ electrons can move by hopping. These $\pi$ electrons allow light absorption, in the case of solar cells, and emission, in the case of OLEDs. Molecular $\pi-\pi^{*}$ orbitals correspond respectively to the Highest Occupied Molecular Orbital (HOMO) and Lowest Unoccupied Molecular Orbital (LUMO). For sake of simplicity, such organic material can be regarded as a semiconductor-like material, where the band gap corresponds to the difference between the LUMO and the HOMO.

Photons absorption by inorganic semiconductors produces free electrons and holes, the charge separation is more difficult in organic semiconductors. When a photon of 
appropriate energy is incident upon organic semiconductor it can be absorbed to produce an excited state called exciton, that is to say an electron-hole pair in a bound state which is transported as a quasi-particle. In organic materials excitons are strongly bounded as a consequence of their low dielectric constant. Organic solar cells belong to the class of photovoltaic cells known as excitonic solar cells [Thompson, Fréchet, Angnew. Chem. Int. Ed., 2008]. The excitons can have appreciable life-time before recombination. To produce photocurrent the electron-hole pair of the exciton must be separated. If not, they can recombine either radiatively (luminescence is a loss mechanism in photovoltaic cells) or non-radiatively with heat production. Therefore after light absorption and exciton formation, the carriers should be separated. Even if not well understand the dissociation occurs at defects, impurities, contacts or any other inhomogeneities. The separation occurs in the electric field induced around the inhomogeneity. If the ionisation takes place at a random defect in a region without an overall electric field, the generated carriers will be lost. To avoid such loss, exciton dissociation should occur in high electric field region associated with a contact or a junction. To produce an internal electric field which occupy a substantial volume of the device, the usual method is to juxtapose two materials with different appropriate properties. One of these materials is an electron donor and the other one is called electron acceptor. The interface between these two materials is called heterojunction. Therefore it is clear that the active donor-acceptor pair governs the separation mechanism. While in the case of inorganic materials the both materials of the heterojunction are clearly identified, the electron acceptor is the n-type material related to its electron excess and the electron donor is the p-type material related to its hole excess, it is not so simple in the case of organic materials. The donor or acceptor nature of an organic semiconductor depends on its carrier mobility which is determined by intrinsic properties of this material. Moreover, it is known that the donor or acceptor character of a material in an organic couple depends also on their relative $\mathrm{HOMO}$ and LUMO values. For instance, $\mathrm{CuPc}$, which is a usually an electron donor, has been also used as electron acceptor with a triphenylamine derivative used as donor [Chen et al., Sol. Energy Mater. Sol. Cells, 2006]. Therefore an organic material with intermediary HOMO and LUMO values can be used as an electron donor for one organic material and as an electron acceptor for another organic material. In figure 3 we can

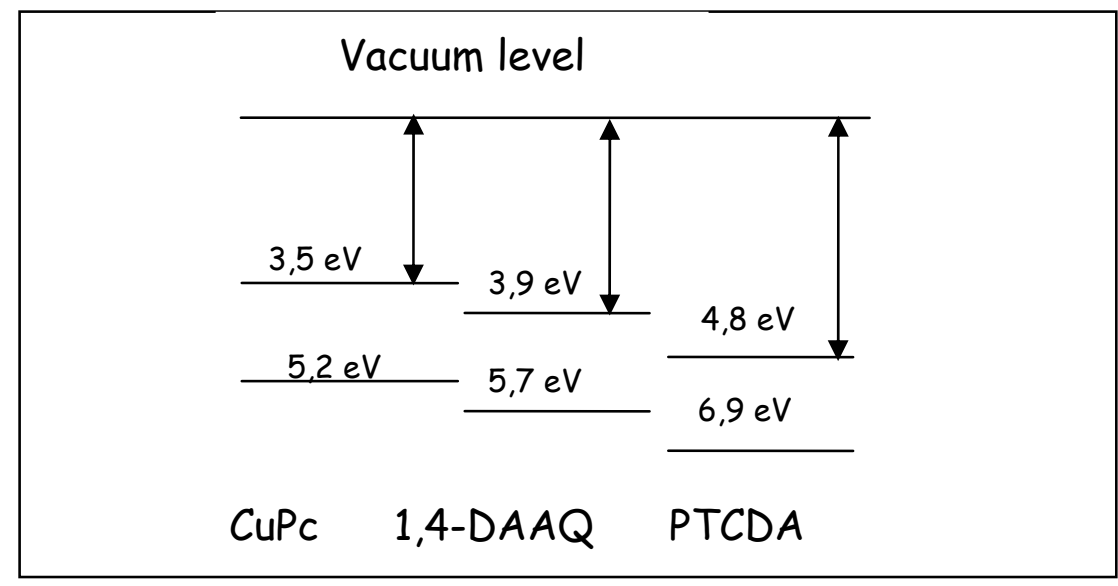

Fig. 3. Relative position of the HOMO and LUMO of CuPc/1,4-DAAQ/PTCDA. 
see the example of the 1,4-diaminoanthraquinone (1,4-DAAQ), which is an acceptor relatively to the copper phthalocyanine $(\mathrm{CuPc})$ and a donor relatively to the perylene 3,4,9,10-tetracarboxylic dianhydride (PTCDA) [Berredjem et al., Dyes and Pigments, 2008].

It is well known that exciton dissociation is efficient at the interface between materials with different electron affinity EA (i.e. LUMO) and ionisation potential IP (i.e. HOMO) (Figure 4). The difference in electron affinities creates a driving force at the interface between the two materials that is strong enough to separate charge carriers of photogenerated excitons. EA and IP of the electron acceptor should be higher than those of the donor.

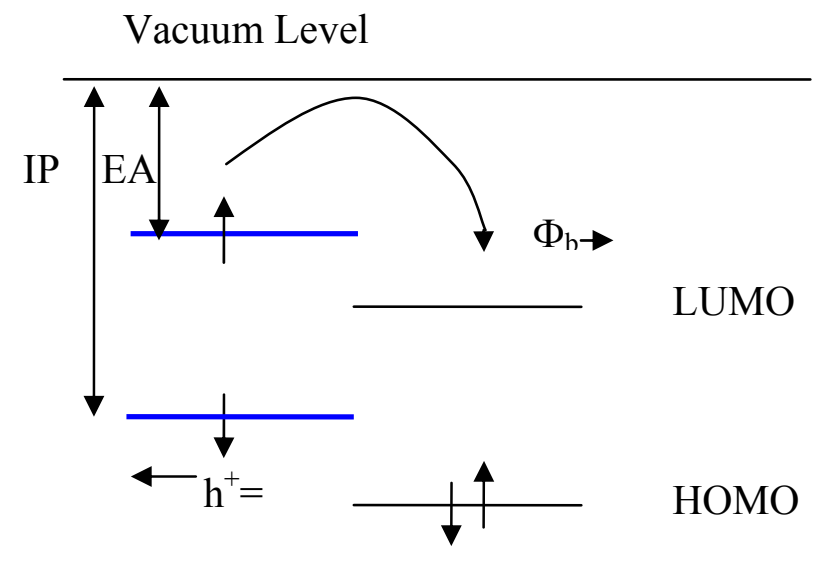

\section{Donor Acceptor}

Fig. 4. Charge separation of an exciton into a free electron/hole pair at a donor acceptor interface.

Then the separated electron and hole should be collected at the cathode and anode electrodes respectively. In a crystalline inorganic semiconductor the LUMOs and HOMOs form the conduction and valence band respectively, and carriers transport within a band. It is usually different in the case of the organic semiconductors. In that case intermolecular forces are Van der Waals forces and no large conduction band and valence band are formed. Therefore the charge transport proceeds by hopping between localized states. This means that charge carrier mobility in organic materials is smaller than that in inorganic semiconductors. Mobility is improved with the molecular ordering in the films, it is reduced by impurities as well as by oxygen traps. Therefore charge transport is improved by improving order, purification and no oxygen contamination.

So, the operations of an organic solar cell can be summarized in five fundamental steps:

1. Photon absorption by the active organic layer to create excitons.

2. Diffusion of the excitons to a donor/acceptor interface.

3. Excitons dissociation at the interface and formation of electron-hole carrier pairs.

4. These free carriers should move toward the cathode (electrons) and the anode (holes).

5. The electrons (holes) should be extracted to the external circuit by the cathode (anode).

Up to 1986 very low power conversion efficiencies were achieved (\#10-6\%) because of low concentration and mobility of free charge carriers. In 1986 Tang reported on a bilayer 
heterojunction solar cell based on the copper-phthalocyanine (CuPc)/perylene tetracarboxylic derivative with 1\% energy conversion efficiency [Tang, Appl. Phys. Lett., 1986]. In spite of numerous efforts to improve the cells performances, there was no breakthrough and it remained around 1\%. However, during the last ten years a new and strong interest has been devoted to organic photovoltaic cells, motivated by two recent developments in the organic semi-conductor field. First it has been shown that the quantum efficiency of the electron transfer from an excited polymer to $\mathrm{C}_{60}$ is very high and the transfer is very fast, [Sariciftci et al., Sciences, 1992; Sariciftci et al., Appl. Phys. Lett., 1993] , which is promising for change carrier separation in PV cells. Secondly the development of efficient organic displays based on organic light emitting devices (OLEDs) has shown that organic electronic components are viable. Those displays are now developed using low cost technology and these new technologies development for OLED can be tested for PV solar cells realisation [Bernède et al., Current Trends in polymer Sciences, 2001]. Therefore OLED technology allows drawing a research guideline in organic PV cells. Since the beginning of the $21^{\text {st }}$ century, power conversion efficiency is increasing rapidly and the organic photovoltaic devices are getting closer to commercialisation [Kim, Lee, Chin, Sol. Energy Mater. Sol. Cells., 2009].

Two technological routes are mainly used: the deposition of polymers and nanoparticles from solution by spin coating technique and the vacuum sublimation of small molecules. The former route has given the concept of bulk heterojunction solar cells (BHJ), while the later gives the multi-heterojunction solar cells family. Development of $\mathrm{BHJ}$ interpenetrating network structures using polymer blended with a fullerene derivative allows overcoming inherent disadvantageous very short exciton diffusion length, which improves significantly cells performances. Controlled morphology of poly-paraphenylene-vinylene/fullerene blend derivatives increased conversion efficiency up to $2.5 \%$ in 2001 [Shaheen et al., Appl. Phys. Lett., 2001]. A post-annealing treatment improved efficiency to 3.5 [Padinger et al., Adv. Funct. Mater., 2003]. To day, the best energy conversion efficiencies ( $>6 \%$ ) have been reach with poly-3(hexyl-thiophene) (P3HT) serving as electron donor and [6,6]-phenyl- $\mathrm{C}_{61}{ }^{-}$ butyric acid methyl ester (PCBM), which is a fullerene derivative as electron acceptor [Kim et al., Science, 2007].

In the multi-heterojunction solar cell family the simplest efficient configuration is based on a bilayer system between two electrodes. About these electrodes, one should be transparent and the other highly reflexive. The bilayer is composed of, at least, one absorbing layer, which is usually an electron donor such as a conjugated polymer or a dye like a metal phthalocyanine and an electron acceptor. Up to now, fullerenes are the best acceptors for organic solar cells [Hoppe and Sariciftci, J. Mater. Res., 2004]. As a matter of fact, they have an energetically deep LUMO, which induces a very high electron affinity relative to numerous organic donors. They exhibit relatively high electron mobility, up to $6 \mathrm{~cm}^{2} / \mathrm{Vs}$ [Anthopoulos et al., Appl. Phys. Lett., 2006, Zhang, Domercq, and Kippelen, Appl. Phys. Lett., 2007]. In the bilayer cells, charge separation predominantly occurs at the organic heterojunction. The built-in potential is determined by the HOMO/LUMO gap energy difference between the two materials contacting to form the heterojunction.

In order to improve the efficiency of planar herojunction structures, either p-i-n or stacked junctions have been probed. The $\mathrm{p}$-i-n heterojunction structure consists of an active intrinsic region sandwiched between a $\mathrm{n}$ and a p-doped layer. [Niggemann et al., Phys. Stat. Sol. (a), 2008]. As said above, usually a metal phthalocyanine is the p-type (electron donor) and 
fullerene the n-type (electron acceptor). The i photoactive layer can be a combination of both [Drechsel et al., Organic electronics, 2004].

As a conclusion of this chapter, in order to facilitate the discussion of the interface behaviour it is helpful to use an equivalent circuit model, which could be helpful in understanding of organic solar cells by providing a quantitative estimation for losses in the cells. The equivalent circuit commonly used to interpret the I-V characteristics of solar cells consists of a photogenerator connected in parallel with a diode, which represents the I-V characteristics in the dark. This corresponds to an ideal model in absence of parasitic resistances.

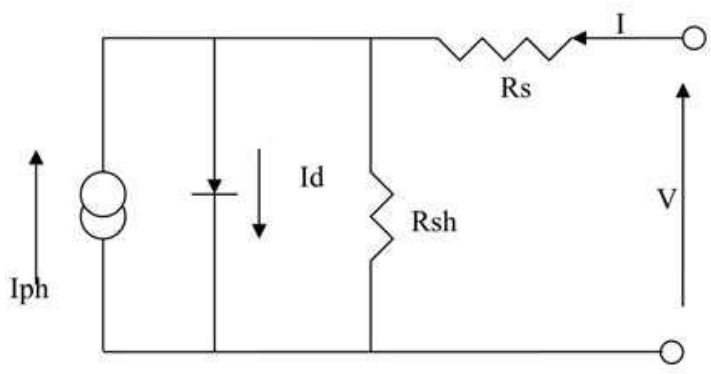

Figure 5 a

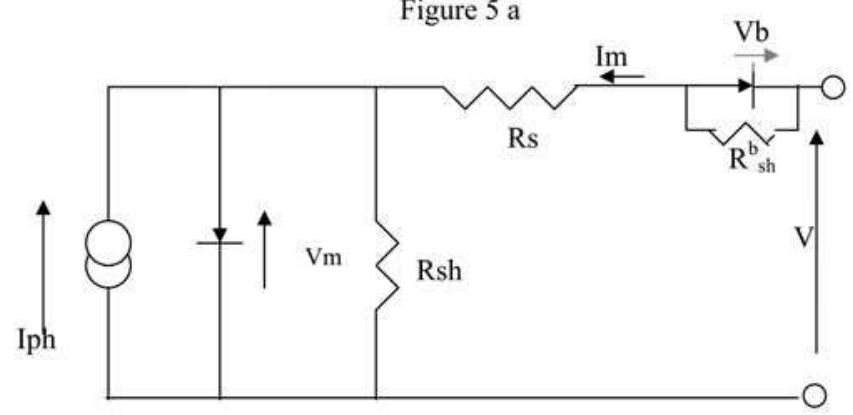

Figure $5 \mathrm{~b}$

Fig. 5. Equivalent circuit of: a-solar cell with ohmic contacts, b-solar cell with rectifying back-contact.

However, in real organic solar cells, it is necessary to introduce a series resistance, Rs, and a shunt resistance, Rsh (Figure 5 a). For such solar cells the mathematical description of this circuit is given by the following equation:

$$
\mathrm{I}=\mathrm{I}_{0}\left[\exp \left(\frac{\mathrm{V}-\mathrm{I} \times \mathrm{Rs}}{\mathrm{nkT}}\right)-1\right]+\frac{\mathrm{V}-\mathrm{I} \times \mathrm{Rs}}{\mathrm{Rsh}}-\mathrm{Iph}
$$

As discussed below, the values of Rs and Rsh depend on the properties of the electrode/organic interfaces.

\section{Impact of electrode/organic interface properties on cells performances}

As shown above organic optoelectronic devices are formed by sandwiching one or more semiconducting organic layers between conducting electrodes. The properties of the 
interface between the organic layers and the electrodes are determinant for the efficiency of the devices. In photovoltaic devices the contact must have good carrier extracting properties. Also electrodes must generate a built-in electric field that is sufficient to collect separated charges. Therefore a good understanding of the interface between the organic layers and the electrodes is crucial to achieve good organic optoelectronic devices.

When a $\pi$-conjugated organic material is put into contact with another material such as electrodes in optoelectronic devices the contact may result in different effects depending on the electrode properties. With a metal which surface is passivated the interaction results in a physisorption with possible integer electron charge transfer. If the metal is non reactive there is possibility of weak chimisorption and possible partial charge transfer. In the case of reactive metal, there is chemisorption with iono-covalent bonding between the metal and the organic material and corresponding partial charge transfert.

Often the surface work function of an electrode depends on the electrode history. The surface work function of a clean metal or TCO can be measured in situ by UPS for exemple $\left(\Phi_{\mathrm{M}}=(5.2 \mathrm{eV}\right.$ for clean gold $)$. However, after air, or only classical vacuum $\left(10^{-3} \mathrm{~Pa}\right)$ exposure there is some physisorbtion at the metal surface which decreases its work function, for instance in place of the $5.2 \mathrm{eV}$ expected, $4.5 \mathrm{eV}$ are often obtained. Therefore air ambient exposure of gold results in a reduction by $0.7 \mathrm{eV}$ of its work function [Braun, Salaneck, and Fahlman, Adv. Mater., 2009]. Similar results have been obtained with TCO. For instance, $\Phi_{\text {ITO }}$ varies from 5 to $4.5 \mathrm{eV}$ depending on the sample history [Li et al., Thins Solid Films, 2005; Johnev, et al., Thins Solid Films 2005]. So, the effective work function of the electrode when put in contact to an organic material may be significantly lower than that expected, which induces unexpected energy level alignment at the organic material/electrode interface. Often, in order to study the energy level alignment at the organic material/electrode interface UPS is used, and samples are grown in-situ to avoid contamination, that is to say all the process takes place under ultra-high vacuum. The result can fail in the attempt to describe the interface band alignment of optoelectronic devices contact, since they are processed under moderate vacuum, neutral gas or even room air conditions. That fact should be kept in mind when one attempts to understand the optoelctronic devices behaviour through UPS studies done in ultra high vacuum.

Energy level alignment at organic material/electrode interfaces is one of the main fundamental issues about the optoelectronic devices. In the light of inorganic semiconductor/metal interfaces the simple Schottky-Mott model has been often applied to organic contacts. The model is presented in Figure 6. When an organic semiconductor is put in contact with an electrode the Schottky-Mott model assumes an alignment of the vacuum level and a band bending in the space charge layer (SCL) to achieve alignment of the bulk Fermi levels. Therefore the barrier height for hole extraction $\Phi_{\mathrm{B}}$ corresponds to:

$$
\Phi_{\mathrm{B}}=\Phi_{\mathrm{M}}-\Phi_{\mathrm{S}}
$$

$\Phi_{\mathrm{S}}$ being the work function of the organic semiconductor (Figure 6).

More generally, if $\phi_{\mathrm{M}}$ is the work function of the metal, i.e. its ionisation potential IP, and $\phi_{\mathrm{S}}$ the work function of the semiconductor, i.e. the energy difference between the Fermi level and the vacuum level, for the semiconductor we will have:

- $\quad$-in the case of n-type semiconductor

- a Schottky-Mott contact if $\phi_{M}>\phi_{S}$, electrons diffuse from the semiconductor to the metal owing to small carrier density in semiconductors and to high carrier density 
in metals, a depletion layer appears in the semiconductor: there is a rectifying contact.

- an ohmic contact if $\phi_{\mathrm{M}}<\phi_{\mathrm{S}}$, electrons diffuse from the metal to the semiconductor. There is a negative accumulation in the n-type semiconductor, no barrier forms, the contact is ohmic.

- $\quad$-in the case of p-type semiconductor

- a Schottky-Mott contact if $\phi_{\mathrm{M}}<\phi_{\mathrm{S}}$, holes diffuse from the semiconductor to the metal. Owing to small carrier density in semiconductors and to high carrier density in metals, a depletion layer appears in the semiconductor: there is a rectifying contact.

- $\quad$ an ohmic contact if $\phi_{\mathrm{M}}>\phi_{\mathrm{s}}$, electrons diffuse from the semiconductor to the metal. There is a positive accumulation in the p-type semiconductor, no barrier forms, the contact is ohmic.
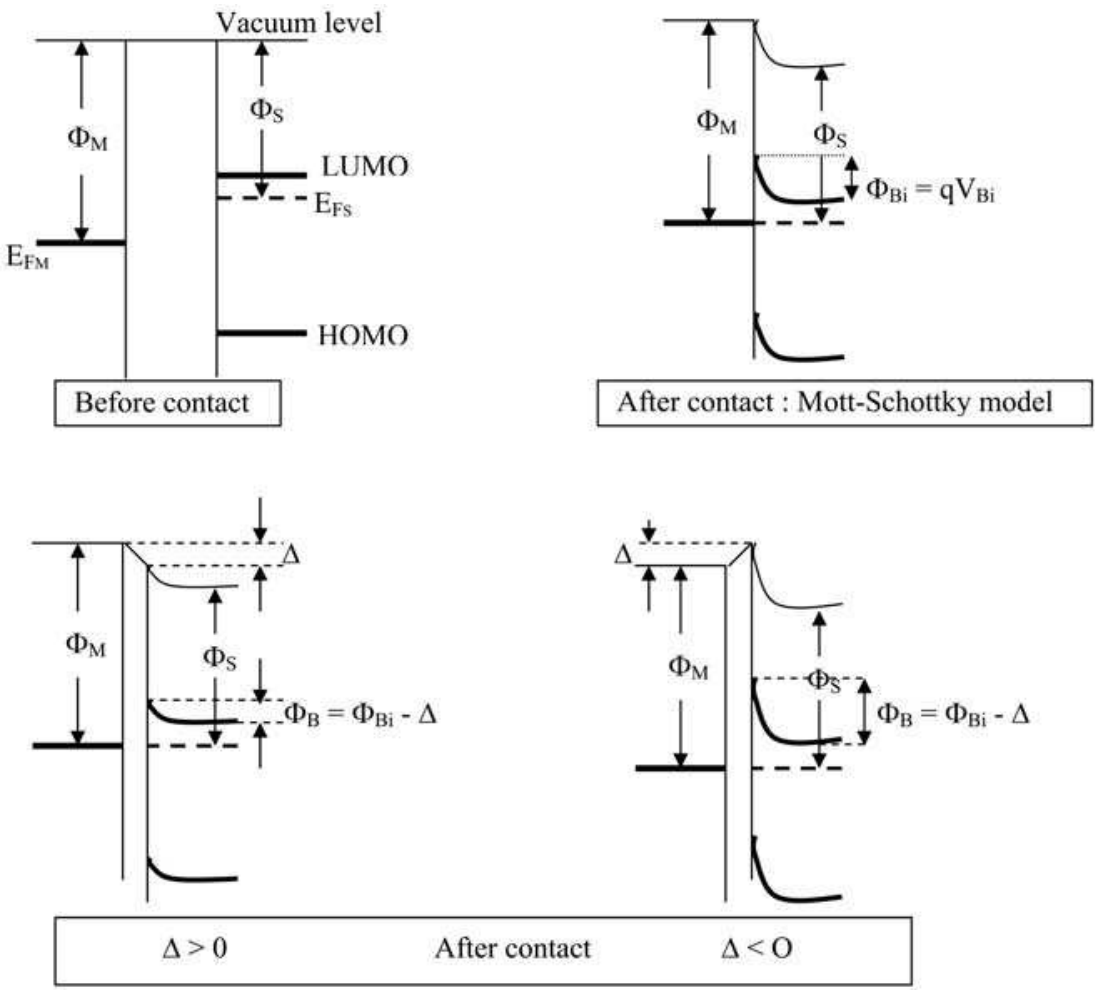

Fig. 6. Interface band alignment, before contact, after contact, without and with an interface dipole

Even if many studies have experimentally demonstrated a strong correlation between the metal work function and the barrier $\Phi_{\mathrm{B}}$ for carriers exchange at electrode/organic material interfaces there is still matter of controversy.

The described Schottky-Mott model is an ideal and simple model, however, real energy level alignment should often consider a vacuum level discontinuity associated with an 
interface dipole, ID, resulting from charge rearrangement upon interface formation [Lee et al., Appl. Phys. Lett., 2009].

In the case of inorganic metal/semiconductor contacts two limit models have been proposed. The Schottky-Mott model where the vacuum level of the organic and metal aligned, forming a region of net space charge at the interface and the Bardeen model, where a large density of surface states induces a pining effect of the Fermi level and the presence at the interface of a barrier independent of the metal work function. The Cowley-Sze model is an intermediate model, where interface states would be induced in the original band gap of the semiconductor upon contact with a metal giving the interfacial dipole $\Delta^{\prime}$. The effective barrier height for hole exchange $\Phi_{\mathrm{b}, \mathrm{eff}}$ is therefore given by :

$$
\Phi_{\mathrm{B}, \mathrm{eff}}=\Phi_{\mathrm{B}}-\Delta^{\prime}
$$

$\Delta^{\prime}$ is proportional to the amount of charge transferred due to energy difference between the metal Fermi level and the charge neutrality level (CNL). If we assume a uniform distribution of metal-induced interface state, it can be shown that $\Phi_{\mathrm{B}, \text { eff }}$ varies linearly with the metal work function with a slope, S, smaller than one [Lee et al., Appl. Phys. Lett,. 2009]. In the absence of metal-induced interface state, the injection barrier follows the Schottky-Mott limit with $S=1$. The other limit corresponds to $S=0$, the interface dipole reaches a saturated value with the organic CNL aligned to the metal's Fermi level. There is Fermi level pining and the variation of the metal work function is fully compensated by the metal-induced interface state dipole.

By analogy with inorganic metal/semiconductor contacts two limit models have been proposed when an organic semiconductor is deposited onto a conducting material. The first is the above described Schottky-Mott simple model. The second proposed that a charge dipole forms on the interface due to effect such as chemical interaction and/or formation of interface states, in that case the vacuum level does not align at the interface. This interface dipole (ID) induces vacuum level shift $\Delta$. Therefore the Mott-Schottky barrier height should be modified by the amount of $\Delta$ :

$$
\Phi_{\mathrm{B}}=\Phi_{\mathrm{M}}-\Phi_{\mathrm{S}}-\Delta
$$

The sign of $\Delta$ depends on the nature of the contact (Figure 6) and it will be discussed below. Moreover, another question is, does band bending occur in organic semiconductors? Following S. Braun and W.R. Salaneck, M. Fahlman [Braun, Salaneck, and Fahlman, Adv. Mater., (2009)] band bending should not be expected for organic semiconductors, as they do not have band structure but localized state featuring hopping transport. Charge can be exchanged at the interface but only organic material in close vicinity to the metal surface takes part in the charge exchange. Yet, they admit that band-bending like behaviour has been demonstrated for $\pi$-conjugated organic thin films deposited on metal substrates. It has been shown that localized energy levels of the organic material are shifted depending on the distance to the metal interface, until depletion region thickness is reached [Nishi et al., Chem. Phys. Lett., (2005); Ishii et al., Phys. Stat. Sol (a), 2004]. Also, J. C. Blakesley and N. C. Greenham [Blakesley and Greenham, J. Appl. Phys., 2009] have shown that there is a good agreement between UPS measurements and theoretical band bending calculations. UPS measurements of thin organic layers on conducting substrates have shown the presence of band bending within a few nanometers [Hwang et al., J. Phys. Chem. C, 2007]. It has been proposed that this band bending effect is due to transfert of carriers from the substrate into 
the organic film. Such integer charge transfer (ICT) at organic/passivated conducting substrate interface has been proposed by Salaneck group [Tengstedt et al., Appl. Phys. Lett. (2006); Fahlman et al., J. Phys.: Condens. Matter, (2009)]. The ICT model proposes that electron transfer via tunnelling through the passivating surface layer, which implies the transfer of an integer amount of charge, one electron at a time. Tunnelling occurs when the substrate work function is greater (smaller) than the formation energy of positively (negatively) charged states in the organic material. The energy of a positive integer charge transfer state $\mathrm{E}_{\mathrm{ICT}+}$ is defined as the energy required to take away one electron from the organic material and, in the case of negative integer, the charge transfer state, $\mathrm{E}_{\text {ICT- }}$ is defined as the energy gained when one electron is added to the organic material. In the case of a positive integer charge transfer, the organic material at the interface becomes positively charged, while the substrate becomes negatively charged, creating an interface dipole $\Delta$ that down-shift the vacuum level. The electron transfer begins when the organic is put into contact with the substrate, and it goes on up until equilibrium is reached, i.e. when $\mathrm{E}_{\mathrm{ICT}+} \Delta$ is equal to the substrate work function (Figure 7).
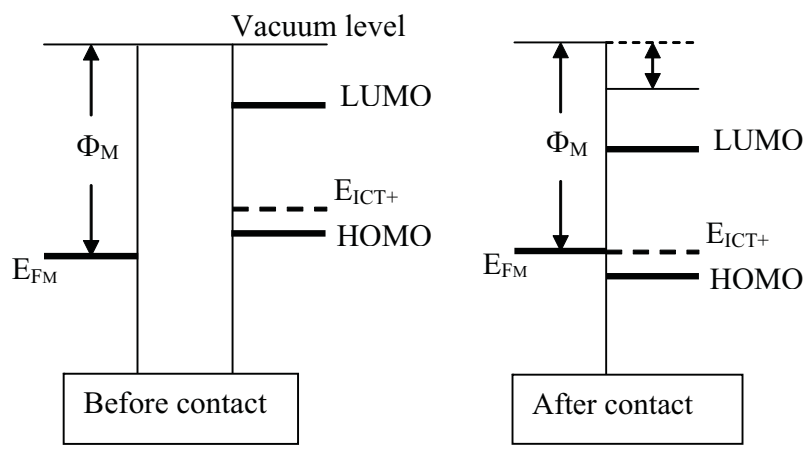

Fig. 7. Integer charge transfer model.

Here also there is some controversy about the formation, or not, of a band bending. However the model predicts the Fermi level pinning experimentally encountered when $\Phi_{M}$

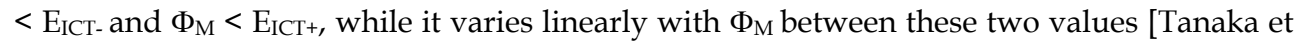
al., Organic Electronics, 2009].

In addition, Fermi level alignment is a critical problem. However in practical situation of organic solar cells, band bending coupled with interface dipole formation have demonstrated their potentiality to account for experimental results.

If the ICT model, with or without band bending, is efficient for passivated surface substrates other models should be used when there is some chemical interaction between the organic and the substrate.

In the case of strong chemisorption, for instance when the metal electrode is deposited by evaporation onto the organic material there is diffusion of metal atoms into the organic film and the situation is quite complicated, since often the organic material may offer different feasible bonding sites for the metal. Chemisorption can be used voluntarily to modify the properties of the substrate surface, typically by using self-assembled monolayers (SAM). SAM will be discussed in the paragraph dedicated to the contact anode/electron donor.

More generally, the chemical bonding between the metal and the organic molecule may involve a transfer of charge which up-shift, when there is an electronic charge transfer to the 
molecule, or down-shift, when there is an electronic charge transfer to the metal, the vacuum level by introducing a dipole-induced potential step at the interface (Figure 8). Therefore here also there is a shift $\Delta$ of the vacuum level at the interface.
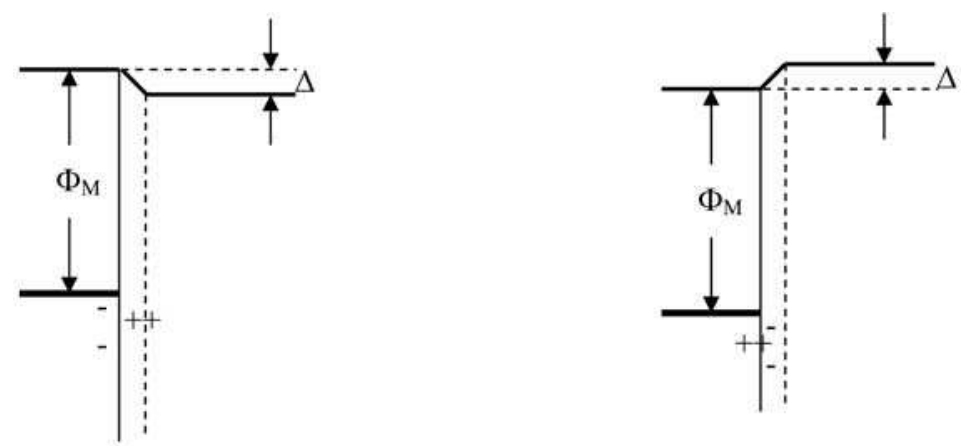

Fig. 8. Interface dipole involved by chemisorption's

As a conclusion it can be said that, whatever its origin, an interface dipole is often present at the interface electrode/organic. Following its sign, this dipole can increase or decrease the potential barrier present at the interface. However, this dipole is only one contribution to the interface barrier, the difference between the work function of the electrode (anode-cathode) and the energy level (HOMO-LUMO) of the organic material is another significant contribution, which allows predicting, at least roughly, the behaviour of the contact.

\section{Interface characterisation techniques}

One key issue for organic optoelectronic is the understanding of the energy-level alignment at organic material/electrode interfaces, which induces, a fortiori, the knowledge of the electrode work function and ionisation potential (HOMO) and electron affinity (LUMO) of organic semiconductors. For the investigation of the chemistry and electronic properties of interfaces X-ray photoelectron spectroscopy (XPS) and ultraviolet photoelectron spectroscopy (UPS) are often used [Braun, Salaneck, and Fahlman, Adv. Mater., 2009]. Energy level alignment at organic/electrode interfaces can be also carefully studied with Kelvin probe [Ishii et al., .Phys. Stat. Sol (a) (2004)]. Cyclic voltammetry is also a valuable tool to estimate the HOMO and LUMO of the organic materials [Cervini et al., Synthetic Metals, 1997; Brovelli et al., Poly. Bull., 2007].

\subsection{Electron spectroscopy for chemical analysis (ESCA): X-ray photoelectron spectroscopy (XPS) and ultraviolet photoelectron spectroscopy (UPS)}

ESCA is a widely used technique for studying chemical and electronic structure of organic materials. More precisely, the method is very useful for the study of surfaces and interfaces. In the case of UPS, the photoelectron inelastic mean free path is less than ten Angstroms.

The well known basic equation used in interpreting photoelectron spectra is:

$$
\mathrm{E}_{\mathrm{B}}=\mathrm{h} v-\mathrm{E}_{\mathrm{kin}}-\Phi_{\mathrm{SP}}
$$

Where $\mathrm{E}_{\mathrm{B}}$ is the binding energy, $\mathrm{h} v$ is the photon energy, $\phi_{\mathrm{SP}}$ spectrometer specific constant (the work function of the spectrometer). Assuming that due to the removal of an electron 
from orbital $\mathrm{i}$ the rest of the electron system is not affected (frozen approximation), $\mathrm{E}_{\mathrm{B}}$ corresponds to orbital energies $-\varepsilon(\mathrm{i})$. However, the remaining electrons in the environment can screen the photohole, which induces an additional relaxation contribution and impacts the measured $E_{B}$ value. Changes in the valence electron density induces small, but significant, shift of the core level binding energy, called chemical shift. Hence, charge transfer and chemical bond formation can be probed using XPS. UPS is used for valence electronic study because the photoionisation cross-section for electrons is orders of magnitude higher in the valence band region for UPS and the photon source (He lamps) has high resolution. The source of photons is either HeI $(\mathrm{h} v=21.2 \mathrm{eV})$ or HeII radiation $(\mathrm{h} v=$ $40.8 \mathrm{eV}$ ). These energies allow for mapping the valence electronic states of organic materials. The UPS spectra give information about the electronic structure of the material and its work function. It also measures the change $\Delta$ of the work function after coverage (Figure 9).

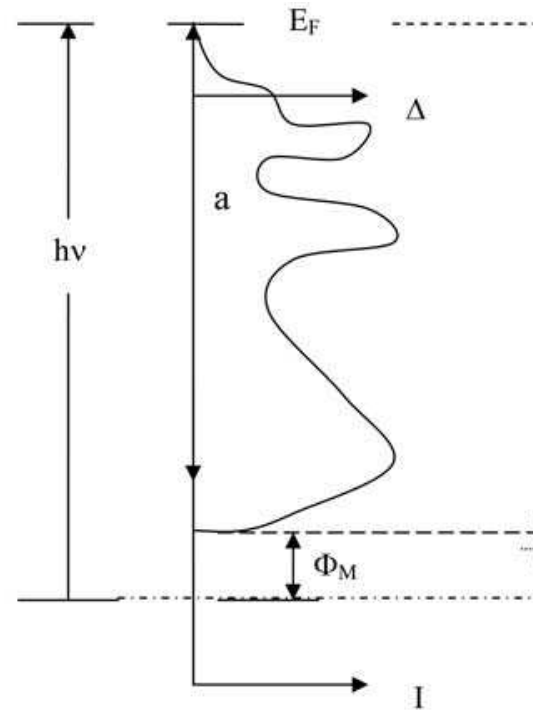

(a)

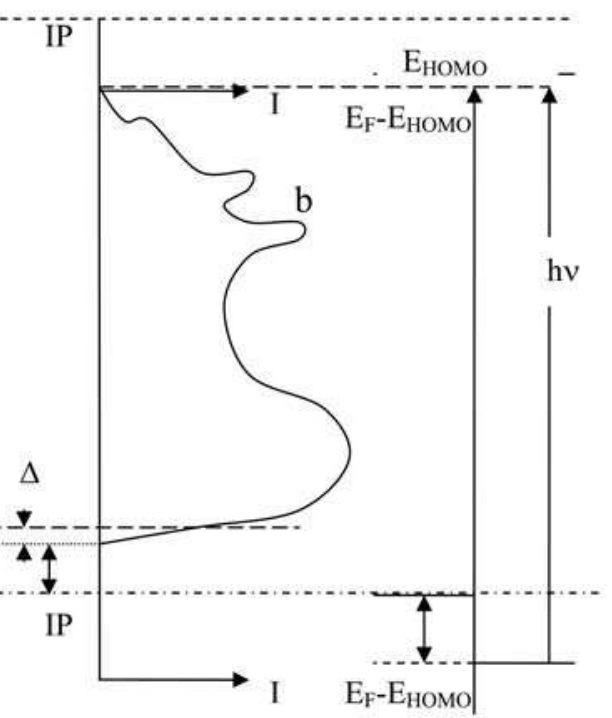

(b)

Fig. 9. Shows the principle of UPS for the study of an interface: a- clean metal, b- metal covered with an organic monolayer.

The UPS spectrum of a clean metal substrate can be seen in Figure 9a. Electrons below the Fermi level are excited by the uv light and emitted into vacuum. The kinetic energy $E_{k i n}$ distribution of the emitted electrons is called the UPS spectrum and reflects the density of the occupied states of the solid.

Only photoelectrons whose kinetic energy is higher than the work function $\phi_{\mathrm{M}}$ of a sample can escape from the surface, consequently $\phi_{\mathrm{M}}$ can be determined by the difference between the photon energy and the width of the spectrum (Figure 9 a). The width of the spectrum is given by the energy separation of the high binding energy cutoff ( $E_{\text {cutoff }}$ ) and the Fermi energy $\left(E_{b}=0\right)$ :

$$
\phi_{\mathrm{M}}=\mathrm{h} v-\mathrm{E}_{\text {cutoff }}
$$


A change in work function, $\Delta$, then can be tracked by remeasuring the $\mathrm{E}_{\text {cutoff }}$ after deposition of an organic monolayer.

Possible shift of the cutoff and thus of the vacuum level suggests the formation of an interfacial dipole layer $\Delta$ [Crispin, Solar Energy Materials \& Solar Cells, 2004; Kugler et al., Chem. Phys. Lett., 1999; Seki, Ito and Ishii, Synthetic Metals, 1997] (Figure 9 b).

In this case the small binding energy onset corresponds to the emission from the highest occupied molecular orbital (HOMO) and the high binding energy (low kinetic energy) cutoff corresponds to the vacuum level at the surface of the organic layer.

Therefore as said above we can visualise the relative position of the energy levels at the interface, and examine the difference of the vacuum level between the metal and organic layer which corresponds to $\Delta$ (Figure 10).

UPS is a very powerful tool to detect the presence-or not- and to measure the interface dipole and therefore to understanding of the energy-level alignment at interfaces organic material/electrode.

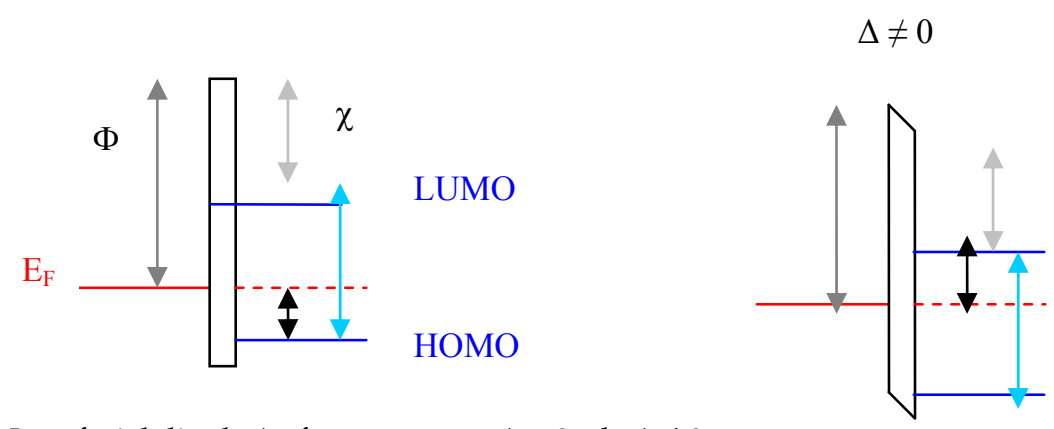

Fig. 10. Interfacial dipole $\Delta$ after contact: a: $\Delta=0, \quad b: \Delta \neq 0$.

\subsection{Kelvin probe}

The principle of Kelvin probe was put in evidence by Lord Kelvin in 1898 [Phil. Mag., 1898]. The principle was first applied, using a vibrating capacitor by Zisman [Zisman, Rev. Sci. Instrum., 1932]. Nowadays, the Kelvin probe method (KPM) is used to measure the work function of various surfaces. The sample and a metallic vibrating reference electrode constitute a capacitor. The vibration of the reference electrode induces an alternative current, this current is zero when the voltage applied to the reference electrode is equal to the contact potential difference between the reference and the sample. When the sample is conductor, there is no difficulty, the surface of the sample works as a plate of the capacitor and charges are accumulated at the surface. It is more complicated when the sample is a semiconductor or an insulating material. Some part of the charge is into the sample, this situation has been discussed by different authors [Ishii et al., Phys. Stat. Sol (a), 2004; Pfeiffer, Leo and Karl, J. Appl. Phys, 1996]. They conclude that the vacuum level of the reference electrode exactly coincides with that of the sample, in the case of null-detection condition. Therefore it can be said that KPM probes the surface potential of the sample with precision. For instance, the energy level alignment at $\mathrm{CuPc} /$ metal interfaces has been studied using KPM [Tanaka et al., Organic Electronics, 2009]. In order to study the vacuum level (VL) shift at $\mathrm{CuPc} /$ metal interfaces different metals presenting a wide range of $\Phi_{\mathrm{M}}$ have been probed. Moreover, the deposition of the CuPc onto the metal was performed in a stepwise manner 
with Kelvin probe measurement at each step to follow the VL shift as a function of the CuPc film thickness. The study showed that the organic layer onto the metal surface plays two important roles in the energy level alignment: formation of an interfacial dipole (ID) and passivation of the metal surface. The deposition of the first nanometers $(<2 \mathrm{~nm})$ induces a large VL shift indicating a charge redistribution at the interface related to the interface dipole (ID) formation. For thicker thickness the VL variation depends on the $\Phi_{M}$ value. When $\Phi_{M}$ is higher than LUMO ${ }_{C u P c}$ very little VL shift occurs for thicker films, the energy level alignment is determined by $\Delta_{\mathrm{ID}}$ and $\Phi_{\mathrm{M}}$. Therefore the barrier height at the interface varies with $\Phi_{M}$. When $\Phi_{M}$ is smaller than $L U M O_{C u P c}$, VL varies up to $5 \mathrm{~nm}$ of $C u P c$, there is a spontaneous charge transfer (CT) from metal to the CuPc until LUMO $\mathrm{CuPc}_{\mathrm{c}}$ is located above the Fermi level. There is a pinning of the Fermi level and the barrier height at the interface does not vary with $\Phi_{M}$. This example shows the KPM could be an efficient tool for studying the interfaces organic materials/electrodes.

\subsection{Cyclic voltammetry}

Electrochemistry is a simple technique, which allows estimating the HOMO and LUMO of organic material [Li et al., Synthetic Metals, 1999].

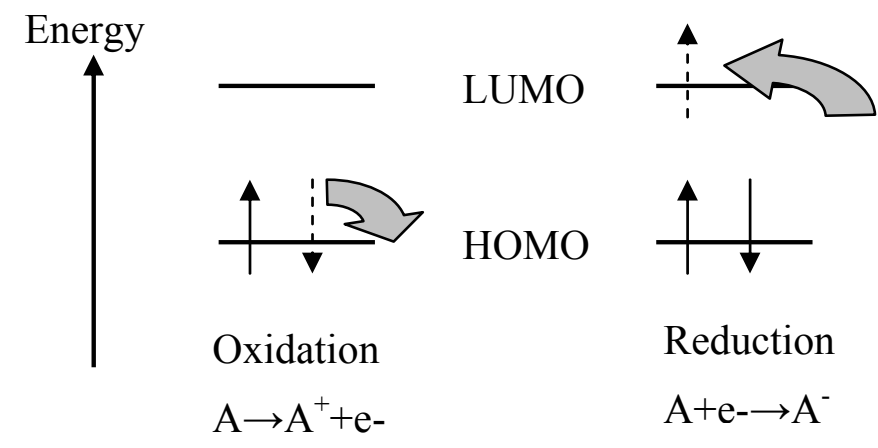

Fig. 11. Oxidation and reduction of an organic molecule.

When the organic material shows an electron reversible reduction and oxidation wave, cyclic voltammetry $(\mathrm{CV})$ is recognised as an important technique for measuring band gaps, electron affinities (LUMO) and potential ionisations (HOMO). The oxidation process corresponds to removal of charge from the HOMO energy level whereas the reduction cycle corresponds to electron addition to the LUMO (Figure 11).

The experimental method is based on cyclic voltammetry [Cervini et al., Synthetic Metals, 1997; Li et al., Synthetic Metals, 1999.]. The electrochemical set up was based on classical three electrodes cells. The reference electrode was $\mathrm{Ag} / \mathrm{AgCl}$.

The electrochemical reduction and oxidation potentials of the organic material are measured by cyclic voltammetry $(\mathrm{CV})$. When the $\mathrm{CV}$ curves showed a one electron reversible reduction and oxidation wave, the HOMO and LUMO energy can be determined from the first oxidation and reduction potential respectively. The potential difference Eg = LUMO $\mathrm{HOMO}$ can be used to estimate the energy gap of the dye. The energy level of the normal hydrogen electrode (NHE) is situated $4.5 \mathrm{eV}$ below the zero vacuum energy level [Brovelli et 
al., Poly. Bull., 200)]. From this energy level of the normal hydrogen and the reduction potential of the reference electrode used, for example $\mathrm{Ag} / \mathrm{AgCl}$ i.e. $0.197 \mathrm{~V}$ versus $\mathrm{NHE}$, a simple relation can be written which allows estimating the both energy values (7):

$$
\begin{aligned}
& \mathrm{LUMO}=[(-4.5)-(0.197-\text { Ered })] \mathrm{eV} . \\
& \mathrm{HOMO}=[(-4.5)-(0.197-\text { Eox })] \mathrm{eV} .
\end{aligned}
$$

As an example the curve corresponding to $\mathrm{N}, \mathrm{N}^{\prime}$-diheptyl-3,4,9,10perylenetetracarboxylicdiimide (PTCDI-C7) is presented Figure 12.

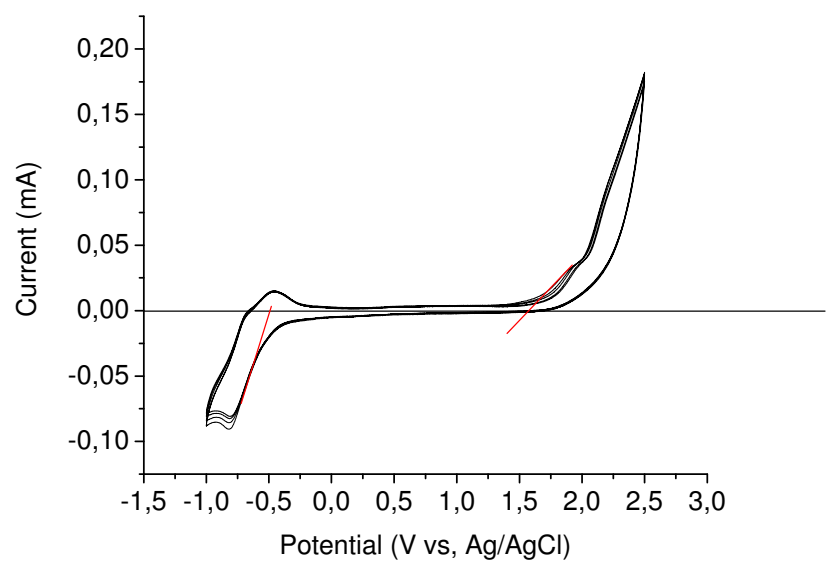

Fig. 12. Cyclic voltammogram of PTCDI-C7 on Pt disc electrode in medium of anhydride dichloromethane.

As working electrode, a polycrystalline platinum disc was used. The reference electrode was $\mathrm{Ag} / \mathrm{AgCl}$ in solution of tetraethylammonium chloride $\left(\mathrm{Et}_{4} \mathrm{NCl}\right)$. The potential was adjusted to $0.199 \mathrm{mV}$ with respect to the normal hydrogen electrode (NHE) [East and del Valle, J. Chem. Educ., 2000]. As counter-electrode, spiral platinum was used in a separated compartment of work electrode by fritted glass

The electrochemical reduction and oxidation potentials of the PTCDI-C7 were measured by cyclic voltammetry (CV) (see Figure 12). From CV curves, PTCDI-C7 in dichloromethane showed a one electron reversible reduction and oxidation waves.

The HOMO and LUMO energy of PTCDI-C7 can be determined from the first oxidation and reduction potential respectively. The potential difference $\mathrm{Eg}=\mathrm{LUMO}-\mathrm{HOMO}$ can be used to estimate the energy gap of the dye. The energy level of the normal hydrogen electrode (NHE) is situated $4.5 \mathrm{eV}$ below the zero vacuum energy level [Bard and Faulkner, Fundamentals and Applications, Wiley 1984]. From this energy level of the normal hydrogen and the reduction potential of the reference electrode used in the present work $\mathrm{Ag} / \mathrm{AgCl}$ i.e. $0.199 \mathrm{~V}$ versus NHE, a simple relation allows us to estimate the both energy values:

$$
\begin{aligned}
& \text { LUMO }=[(-4.5)-(0.199-\text { Ered })] \mathrm{eV} \\
& \mathrm{HOMO}=[(-4.5)-(0.199-E o x)] \mathrm{eV}
\end{aligned}
$$


The values of oxidation and reduction potential are $1.57 \mathrm{~V}$ and $-0.38 \mathrm{~V}$ respectively. Relatively to the vacuum level the energy values of $\mathrm{HOMO}$ and LUMO levels are $-6.30 \mathrm{eV}$ and $-4.30 \mathrm{eV}$ respectively. Therefore the band gap estimated from the electrochemical measurements is $2.0 \mathrm{eV}$. This value is only slightly higher than the optical band gap of a PTCDI-C7 thin film $(1.95 \mathrm{eV})$. So, the energy gap calculated from the difference between the LUMO and HUMO energies is quite close to the optical band gap, which testifies that the cyclic voltammetry provides a useful rough estimate for the location of the LUMO and the HOMO of the organic materials.

\section{Interface organic acceptor/cathode}

For electron injection (OLED) or collection (solar cells) it is necessary to incorporate a low work function as cathode. However low work function metals such as $\mathrm{Mg}, \mathrm{Li}, \mathrm{Ca} . .$. are not suitable because they have high reactivity in air. Historically works on OLEDs have shown that aluminium coupled with LiF is a very efficient cathode. Hung et al. [Hung, Tang and Mason, Appl. Phys. Lett. 2008] have shown that when an ultra thin (1 nm) LiF layer is deposited onto the organic material before $\mathrm{Al}$, this $\mathrm{LiF} / \mathrm{Al}$ bilayer cathode greatly improved the electron injection and reduced the threshold voltage.

The increase in luminance and efficiency is attributed to enhancement of the electron injection from the aluminium into the organic acceptor. The $\mathrm{LiF} / \mathrm{Al}$ cathode improves injection by raising the Fermi energy and shifting the effective injection interface deeper into the organic film [Baldo and Forrest, Phys. Rev., 2001.]. Effectively there is Li doping of the organic layer during $\mathrm{Al}$ deposition.

In the case of solar cells, insertion of a thin $\mathrm{LiF}$ layer $(<1.5 \mathrm{~nm})$ at the organic/aluminium interface allows improving the power conversion efficiency of the cells. An increase in the forward current and in the fill factor is observed upon reducing the serial resistivity across the contact. The optimum LiF thin film thickness is around $1 \mathrm{~nm}$. For higher values the high resistivity of the LiF decreases its beneficial influence. From (I-V) curves it has been estimated that the insertion of a thin $\mathrm{LiF}$ layer decreases the serial resistivity of the diodes by a factor 3-4, while the shunt resistivity is stable [Brabec et al., Appl. Phys. Lett., (2002).]. The precise mechanism of $\mathrm{LiF}$ on the interface properties is still under discussion. Moreover, it should be highlighted that, in the case of solar cells, LiF is not as successful as in the case of OLEDs. Therefore a lot of works have been dedicated at the improvement of the organic acceptor/cathode interface. Different buffer layers have been probed and the main results are summarized below.

We have seen that the maximum value of $\mathrm{Voc}$ is $\mathrm{Voc} \leq \mathrm{LUMO}_{\mathrm{A}}-\mathrm{HOMO}_{\mathrm{D}}$. The same dependence of $\mathrm{Voc}$ with $\mathrm{LUMO}_{\mathrm{A}}-\mathrm{HOMO}_{\mathrm{D}}$ has been encountered whatever the structure used, bulk heterojunction or multiheterojunction structures. The same controversy on the dependence of Voc with the cathode work function [Chan et al., Appl. Phys. Lett., 2007; Rand, Burk and Forrest, Phys. Rev., 2007] is present for both structure families. Indeed, if the Voc value is effectively related to $\Delta\left(\mathrm{LUMO}_{\mathrm{A}}-\mathrm{HOMO}_{\mathrm{D}}\right)$, it depends also of others parameters such as the dark current (leakage current), Voc decreases when this current increases, that is to say when the shunt resistance, Rsh, is faint (Figure 5). In order to check the variation of Voc with $\Delta\left(\mathrm{LUMO}_{\mathrm{A}}-\mathrm{HOMO}_{\mathrm{D}}\right)$ and Rsh, we have studied a cell family with the structure ITO/Donor $/$ Acceptor $/ \mathrm{Al} / \mathrm{P}$, with donor $=\mathrm{ZnPc}$ or $\mathrm{CuPc}$, acceptor $=\mathrm{C}_{60}$, PTCDA, PTCDI$\mathrm{C} 7$ and 1,4-DAAQ and $\mathrm{P}$ a protective layer from oxygen and humidity contamination, which allows keeping the device in room air after assembling. $P_{I}$ corresponds to an encapsulation 
before breaking the vacuum and $\mathrm{P}_{\mathrm{A}}$ an encapsulation after $5 \mathrm{~min}$ of room air exposure [Karst and Bernède, Phys. Stat. Sol. (a), 2006]. While in the former case there is no aluminium post depot oxidation, at least during the first hours of air exposure, in the latter case, $5 \mathrm{~min}$ of air exposure induces air diffusion at the grain boundaries of the polycrystalline $\mathrm{Al}$ layer and formation of a thin $\mathrm{Al}_{2} \mathrm{O}_{3}$ between the anode and the organic material.

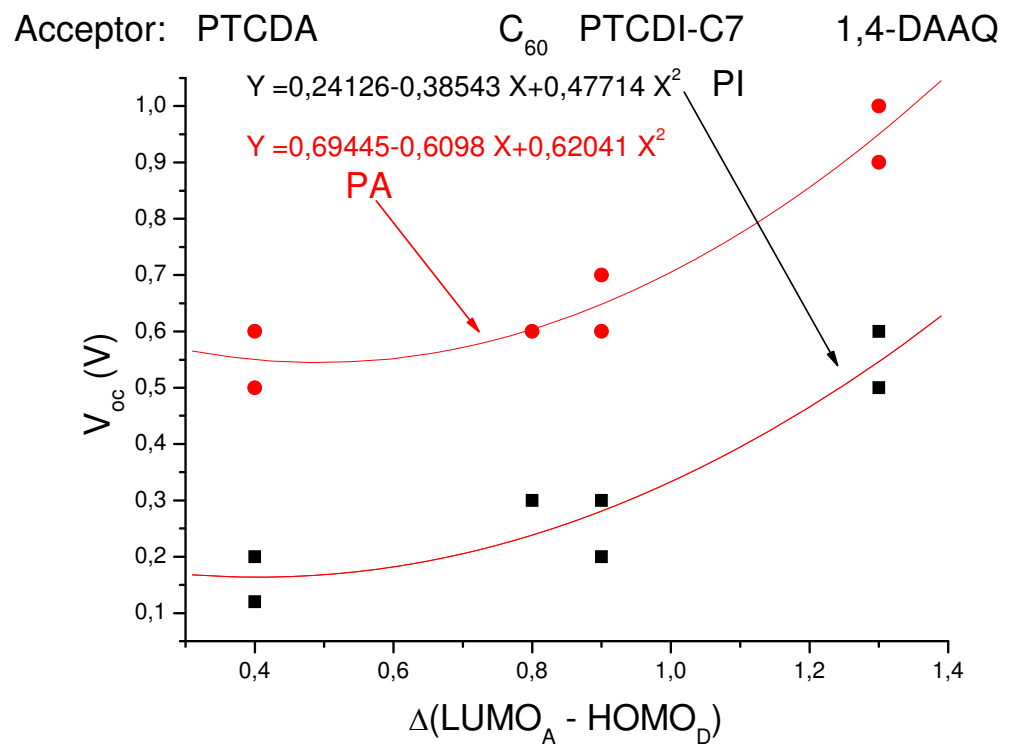

Fig. 13. Voc variation with $\Delta\left(\mathrm{LUMO}_{\mathrm{A}}-\mathrm{HOMO}_{\mathrm{D}}\right)$.

The results are summarized in Figure 13. It can be seen that, as expected, the Voc value increases with the $\Delta\left(\mathrm{LUMO}_{\mathrm{A}}-\mathrm{HOMO} \mathrm{D}\right)$. However, it can be seen also that two curve families are clearly visible. One with small Voc values, which corresponds to cell encapsulated without breaking the vacuum and another with higher Voc values, which corresponds to cells encapsulated after $5 \mathrm{~min}$ of air exposure. The two curves are nearly parallel, which demonstrates that the same phenomenon is at the origin of the Voc increase. Since the only difference between these two families is the contact or not with room air, the translation of the curve should be attributed to the presence of the thin natural $\mathrm{Al}_{2} \mathrm{O}_{3}$ layer at the electron acceptor/aluminium interface. This natural oxide does not depend on the organic material but only on the alumium electrode air exposure, which is in good agreement with the translation effect of the two curves. Such ultra thin $\mathrm{Al}_{2} \mathrm{O}_{3}$ layer $(1 \mathrm{~nm})$ increases the shunt resistance value, which justifies the Voc value increase. Such effect of aluminium oxidation on the open circuit voltage has already been proposed by Singh and coll.[Singh et al., Appl. Phys. Lett., 2005; Singh et al., Sol. Energy Mater. Sol. Cells, 2006], thanks to our in situ encapsulation process we have directly put this effect in evidence. However, if the increase of the shunt resistance of the cells through insulating oxide formation at the interface cathode/organic materiel, allows increasing the open circuit 
voltage and therefore the solar cells efficiency, the limit of the positive effect of such oxide layer is rapidly achieved. Indeed, it is only efficient when electrons can tunnel through the oxide layer. Beyond $2.5 \mathrm{~nm}$, not only the shunt resistance increases but also the series resistance and therefore the current and cell efficiency.

Moreover other limitation at the interface organic/cathode has been highlighted through the experiments described below. It has been shown that one way for circumventing the diffusion length limitation is to use cells with multiple interfaces. Peumans et al. [Peumans et al., Appl. Phys. Lett., 2000] have shown that the introduction of a thin large band gap organic material allows improving significantly the device performances. He called electron blocking layer (EBL) this thin film, because its bandgap was substantially larger than those of the organic donor and acceptor, which block excitons in the organic semiconducting layer far from the cathode avoiding any quenching effect at the cathode/organic interface. Will see more precisely the effect of this "EBL", but first we will conclude on the effectiveness of the very thin oxide layer between the cathode and the organic electron acceptor. In order to discriminate between the effect of an EBL and an oxide layer deposited before the cathode we have worked with ITO/CuPc/ $\mathrm{C}_{60} / \mathrm{Alq}_{3} / \mathrm{Al} / \mathrm{P}, \mathrm{Alq}_{3}$ being used as $\mathrm{EBL}$ layer. It is shown in Table 1, that, as expected, the EBL improve significantly the cells performances, while the encapsulation process does not modify the strongly the I-V characteristics.

\begin{tabular}{|c|c|c|c|}
\hline Devices & Jsc $\left(\mathrm{mA} / \mathrm{cm}^{2}\right)$ & Voc $(\mathrm{V})$ & $\operatorname{Rsh}(\Omega)$ \\
\hline $\mathrm{ITO} / \mathrm{CuPc} / \mathrm{C}_{60} / \mathrm{Al} / \mathrm{PI}$ & 4.75 & 0.24 & 90 \\
\hline $\mathrm{ITO} / \mathrm{CuPc} / \mathrm{C}_{60} / \mathrm{Al} / \mathrm{PA}$ & 4.40 & 0.41 & 1650 \\
\hline $\mathrm{ITO} / \mathrm{CuPc} / \mathrm{C}_{60} / \mathrm{Alq}_{3} / \mathrm{Al} / \mathrm{PI}$ & 7.75 & 0.45 & 1800 \\
\hline $\mathrm{ITO} / \mathrm{CuPc} / \mathrm{C}_{60} / \mathrm{Alq}_{3} / \mathrm{Al} / \mathrm{PA}$ & 7.45 & 0.48 & 1850 \\
\hline
\end{tabular}

Table 1. Jsc and Voc values of the different devices under AM1.5 conditions.

In fact, the Voc value in the presence of $\mathrm{Alq}_{3}$ does not depend strongly on the encapsulation process, while it does when simple $\mathrm{CuPc} / \mathrm{C}_{60}$ junction is used. This difference can be explained by the variation of the value of the shunt resistance, Rsh. Without $\mathrm{Alq}_{3}$, a thin $\mathrm{Al}_{2} \mathrm{O}_{3}$ layer is necessary to improve Rsh and therefore Voc, with $\mathrm{Alq}_{3}$, Rsh is sufficient and the alumina is not necessary to optimise the Voc value (Table 1).

Accordingly to the present discussion, the EBL is sufficient to confine the photogenerated excitons to the domain near the interface where the dissociation takes place and prevents parasitic exciton quenching at the photosensitive organic/electrode interface. Also it limits the volume over which excitons may diffuse. For vapor deposited multilayer structures, a significant increase in efficiency occurs upon the insertion of the exciton blocking interfacial layer, interfacial layer, between the cathode and the electron acceptor film. Bathocuproine (BCP) is often used as exciton blocking buffer layer [Peumans et al., Appl. Phys. Lett., 2000; Huang et al., J.Appl. Phys., 2009]. However, with time, BCP tends to crystallize, which induces some OSCs performance degradation [Song et al., Chem. Phys. Lett., 2005]. Consequently, either other more conductive [Refs] or more stable, e.g, aluminium tris(8hydroxyquinoline) (Alq 3 ), materials have been tested as EBL [Song et al., Chem. Phys. Lett., 2005; Hong, Huang and Zeng, Chem. Phys. Lett,., 2006; Bernède and al., Appl. Phys. Lett., 2008]. Therefore, many organic materials with quite different HOMO and LUMO values can be used as EBL. Indeed, it appears that EBL can also protect the electron accepting film from atoms diffusion during deposition of the electrode. Also it is thick enough and sufficiently 
homogeneous to fill pinholes and others shorting effect which increases Rsh and therefore Voc and the cell efficiency. Therefore the EBL protects the fragile organic films from damage produced during electrode deposition onto the organic material. The large band gap of the EBL, larger than that of the adjacent organic film, allows blocking the excitons in this film. If the EBL blocks the excitons it should not block all charge carriers. Therefore the EBL should be chosen so that it allows electrons collection at the cathode. However the offset energy of the highest occupied molecular orbital (HOMO) of the electron donor (often the fullerene) and the EBL (such as the bathocuproine) is large. Moreover, the optimum EBL thickness is around $8 \mathrm{~nm}$, which is too thick to allow high tunnelling current. So, even if the EBL is an electron conducting material, the difference of the LUMO levels of $C_{60}$ and $A_{1 q_{3}}$ implies that electrons must overcome a large energy barrier to reach the $\mathrm{Al}$ cathode in case of electron transport via LUMO levels (Figure 14-1). More probably, the charge transport in the EBL is due to damage induced during deposition of the cathode, which introduces conducting levels below its LUMO (Figure 14-2) and explains the reason why the transport of electron is not weakened. [Rand et al., Adv. Mater., 2005]. As a conclusion, the EBL, not only block the excitons far from the cathode where they can be quenched, but also prevents damage of the electron acceptor film during cathode deposition. It should be transparent to the solar spectrum to act as a spacer between the photoactive region and the metallic cathode and it must transport electrons to avoid high series resistance. The EBL is also important for fabricating large-area devices with a low density of electrical shorts.

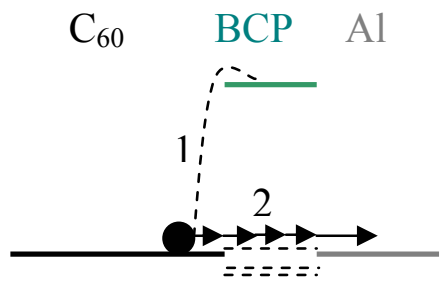

Fig. 14. Band schemes of organic films and cathode contact.

\section{Anode/organic donor interface}

Globally, the electrodes in contact with the organic materials have great importance in the device behaviour. Of course, in optoelectronic devices it is necessary to allow the maximum amount of photons of the solar spectrum to enter the active part of the device. Therefore it is necessary that at least one of the electrodes should exhibit high transparency and should not be reflecting. In classical configuration the transparent electrode, a transparent conductive oxide thin film (TCO), is the anode. Typically, glass coated with the degenerate semiconductor indium-tin oxide (ITO), is used as anode electrode. ITO, which commonly serves as anode in organic optoelectronic devices, attracted considerable interest due to its unique characteristics of high conductivity, good transparency in the visible domain and easy patterning ability, moreover it is commercially available. 
A crucial point in organic devices is the interface between the inorganic electrodes and the organic materials. The key parameter at the anode interface is the hole collection from the organic semiconductor to the anode. A barrier for carrier transport is often present at the interface. It is usually determined by the electrode/organic band offset, that is to say, in the case of holes, the difference between the work function of the anode and the highest occupied molecular orbital (HOMO) of the electron donor, even if, as discussed above, the barrier height depends also of the presence, or not, of an interface dipole. About the influence of the barrier height at the interface anode/organic donor Kang et al [Kang, Tan and Silva, Organic Electronics, 2009] have shown a clear relation between the work function of the anode and the devices performances. They show that the energy conversion efficiency of the cells follows the variation of the value of the anode work function. The work function was measured by Kelvin probe, the anode, ITO/PTFE (polytetrafluoroethylene), was treated with different UV exposure time. The work function increases during the first five minutes and then decreases, also the devices performances and mainly the short circuit current Jsc. High Jsc in organic solar cells are mainly due to small barrier height between the anode and the organic and subsequently improved carriers extraction process. Therefore, the influence of the barrier height at the contact anode/electron donor being well established, it is necessary to control the work function of the anode to achieve good band alignment and ohmic contact. High work function anode is desirable to decrease the series resistance. High and reproducible work functions are difficult to obtain for ITO [Bruner et al., J. Am. Chem. Soc., 2002]. Many processes have been proposed to achieve this goal. First, as discussed in paragraph 3, it should be underlined that ITO work function depends strongly of the thin film history and it is quite difficult to predict. It has been shown that ITO surface chemistry is difficult to control, because its surface is covered by hydrolysed oxides [Armstrong et al., Thin Solid Films, 2004), Donley et al., Langmuir (2002); Kim, Friend \& Cacialli, J. Appl. Phys., 1999]. In fact, he surface chemical functionality of ITO is not well understood [Katkova et al., Appl. Surf. Sciences, 2008]. Authors propose the presence of hydroxyl [Purvis et al., J. Am. Chem. Soc,. (2000)] others not [Chaney \& Pehrsson, Appl. Surf. Sci., 2003]. What is clear for all experimenters in the field of organic optoelectronic devices is that cleanliness of the ITO surface is critically important for efficient hole exchange at the organic material/ITO interface. Devices performances, not only depend on the surface treatment but also on the deposition batches [Berredjem et al., The European Physical Journal: Applied Physics, 2008].

Moreover, it is well known that crystals in polycrystalline ITO thin films have pyramidal shape, which induces a significant surface roughness (some $\mathrm{nm}$ ) of these films. This surface roughness is often evocated as a source of leakage current and lifetime limitation in optoelectronic devices. Also, ITO electrodes were reported to interact chemically, which contributes to the degradation of optoelectronic devices performances [Kugleret al., Synthetic Metals, 1997)]. For instance, even in the absence of oxygen and moisture, oxidation of organic material in contact with ITO has been reported [Scott et al., J. Appl. Phys.1997]. It appears that ITO anode serves as source of oxygen. At least, it should be underlined that ITO, is not ideal due to the scarcity of its main component: indium. Indeed, to day, ITO is widely used as electrode in optoelectronic devices and demand for indium is expected to outstrip supply these years, making devices based on ITO expensive. All that justifies, not only the different works dedicated to ITO surface treatment itself, but also original works on different TCOs and transparent anodes.

First of all different surface treatments of ITO have been probed. Hydrogen peroxide treatment improves the devices performance through work function increase $\left(4.7<\Phi_{M}<4.8\right.$ 
$\mathrm{eV}$ ), however, even with similar $\Phi_{\mathrm{M}}$, different turn-on voltage are measured. Obviously, additional factors should be considered such as surface roughness performance [Kugleret al., Synthetic Metals, 1997]. Different acidic solutions have been probed $\left(\mathrm{HCl}, \mathrm{H}_{3} \mathrm{PO}_{4}\right)$.

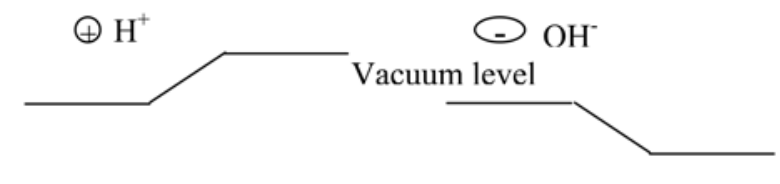

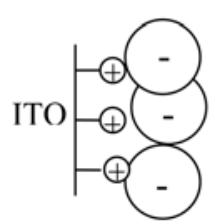

(a)

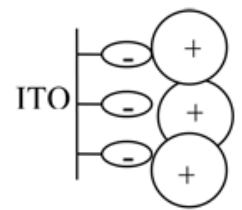

(b)

Fig. 15. Surface structure of passivated ITO for acid (a) and base (b) treatment.

Treatments with phosphoric acid lead to an increase in work function of about $0.7 \mathrm{eV}$ (4.5 to $5.2 \mathrm{eV}$ ) with good homogeneity [Johnev et al., Thin Solid Films, 2005)].

Such effect is induced by monolayer adsorption (Figure 15 a), which allows improving the solar cells efficiency from 1.2 to $1.5 \%$.

However this efficiency remains smaller than that obtained with conducting polymer buffer layer, which will be discussed below. When treated by a base a decrease of $\Phi_{M}$ is obtained, which means that $\Phi_{\mathrm{M}}$ can be shifted of $1 \mathrm{eV}$ [Nüesch et al., Appl. Phys. Lett,. 74 1999]. Moreover, it is necessary to use an appropriate plasma treatment before chemical adsorption. As a matter of fact, plasma treatments are often used to increase the ITO work function. In the case of plasma treatment, after chemical pre-cleaning, the sample was treated by RF plasma, usually the ambient gas is $\mathrm{Ar}$ or $\mathrm{O}_{2}$, with better results achieved with $\mathrm{O}_{2}$. Not only the plasma treatment cleans the ITO surface, increases $\Phi_{M}$, but also smoothes the film surface, whole things resulting in performance improvement of devices [Lu \& Yokoyama, Journ. Crys. Growth, 2004, Zhong \& Jiang, Phys. Stat. Sol. (a), 2006]. Another well known technique used to tune the ITO surface work function, is the deposition of selfassembled monolayers (SAM) onto the ITO film surface. A SAM consists of a molecular backbone terminated by an anchoring group and, at the other extremity, by an end group that may induce a dipole, $\Delta_{\mathrm{SAM}}$. $\Delta_{\mathrm{SAM}}$ is defined as positive if it up-shifts the vacuum level on the organic/SAM side. Different organic material families can be used as SAM, tin phenoxides [Bruner et al., J. Am. Chem. Soc., 2002], thiophene phosphonates, phosphonic acids [Hansson et al., J. Am. Chem. Soc., 2005; Sharma et al., J. Appl. Phys., 2009], also polymeric (LBL) assembly has been used for anode modification layer by layer [Kato, J. Am. Chem. Soc., (2005].

If these chemical techniques allow tuning efficiently the work function of the ITO thin films, physical techniques such as spin coating, vapor deposition can be used also with success.

The conducting polymer the most widely used to help the charge transporting at the interface ITO/organic is the poly(ethylene dioxythiophene) doped with polystyrene sulfonic acid (PEDOT:PSS) [Hoppe and Sariciftci, J. Mater. Res., 2004]. PEDOT:PSS is a p-type semiconductor, a good hole transport material, it is soluble in water and easy to depose by spin coating. Its work function is $5.2 \mathrm{eV}$. 
The initial solution of PEDOT-PSS is $3 \mathrm{wt}$. \% in water. It is spun at 2000-5000 rpm to form a 50-100 nm thick layer. After deposition, to prevent the presence of water in the device, PEDOT:PSS coated ITO is annealed for half to an hour at $100-150^{\circ} \mathrm{C}$. Then the different organic constituents and the cathode of the optoelectronic device are deposited. The PEDOT:PSS buffer layer allows the device performance to be significantly improved, OLEDs and solar cells. It is admitted that the high value of its work function allows a good band alignment with the HOMO of the electron donor, which decreases the barrier height at the interface and therefore assures a better hole collection from the polymer into the ITO electrode. Also it is supposed that the PEDOT:PSS spin coated onto the ITO surface smoothes its surface and, therefore, any possible short circuiting due to the spiky roughness of the ITO surface is prevented. It improves the contact between the polymer and the ITO. It is admitted that this buffer layer enhances adhesion to the organic layer. Also it prevents direct contact between the oxygen of the ITO and the organic material.

However, PEDOT:PSS is problematic since its poor conductivity is a major limiting factor for device performance and it degrades under UV illumination [Chang \& Chen, Appl. Phys. Lett,. 2007; Kang et al., J. Phys. D: Appl. Phys., 2008]. Even after baking, due to its hygroscopic nature some amount of water always appears in PEDOT:PSS, which introduces water into the active layer, it is also slightly acidic [Van de Lagemaat et al., Appl. Phys. Lett., 2006, Johnev et al., Thin Solid Films, 2005]. Moreover, not only the depositing process from aqueous solution introduces impurities but the reproducibility is in need of improvement [Johnev et al., Thin Solid Films, 2005].

Therefore, other solutions have been proposed, each one based on original buffer layers such as metal or oxides. Some attempts using thin metal buffer layers have been done during the last years, however the results were quite disappointing, the metal thin film used being thick of some nanometers, the transmission of the visible light decreases significantly (Figure 16) and also the devices efficiency [Yoo et al., Synthetic Metals, 2005].

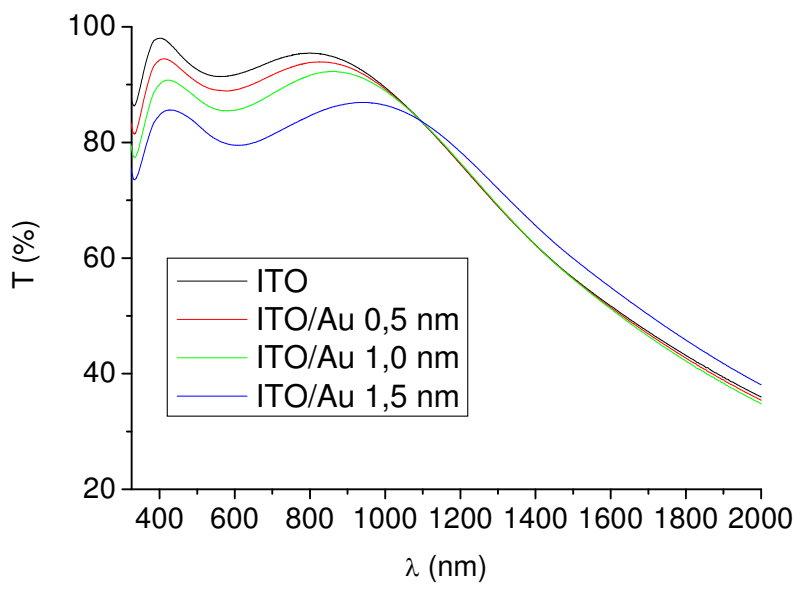

Fig. 16. Variation of the transmittance of ITO/Au structures with the Au thickness (0 to 1.5 $\mathrm{nm})$. 
We have shown that this difficulty could be overcome by using an ultra thin $(0.5 \mathrm{~nm})$ gold film. The introduction of this ultra-thin metal layer at the interface anode/electron donor allows improving significantly the energy conversion efficiency of the organic solar cells [Bernède et al., Appl. Phys. Lett., 2008; Bernède et al., Sol. Energy Mater. Sol. Cells, 2008].

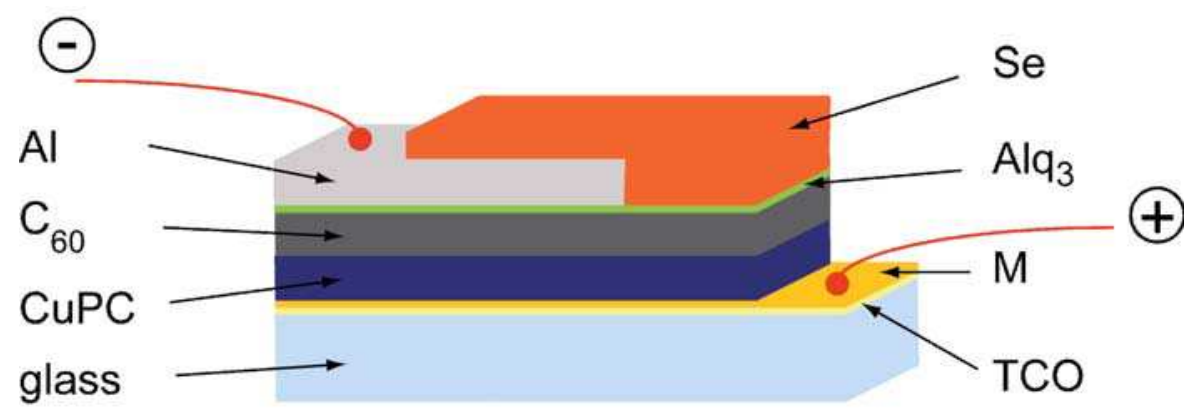

Fig. 17. Schematic structure of the fabricated solar cells with the ultra-thin gold layer onto the TCO.

The efficiency improvement is even more remarkable as regards to TCO initial quality. The effect of this ultra-thin metal buffer layer has been probed on multi-heterojunction organic solar cells (Figure 17) and we present, with more details, this example of efficient buffer layer at the interface anode/electron donor. The electron donor used was copper phthalocyanine $(\mathrm{CuPc})$ (some attempts have been done using pentacene and similar behaviour has been obtained), the electron acceptor was fullerene $\left(\mathrm{C}_{60}\right)$ and the electron blocking layer was the tris(8-hydroxyquinoline) ( $\mathrm{Alq}_{3}$ ) [Kim et al., Sciences, 2007, Berredjem et al., Eur. Phys. Journ.: App. Phys. 2007]. CuPc, $\mathrm{C}_{60}$ and $\mathrm{Alq}_{3}$ have been deposited in a vacuum of $10^{-4} \mathrm{~Pa}$. The thin film deposition rate and thickness were estimated in situ with a quartz monitor. The deposition rate and final thickness were $0.05 \mathrm{~nm} / \mathrm{s}$ and $35 \mathrm{~nm}$ in the case of $\mathrm{CuPc}, 0.05 \mathrm{~nm} / \mathrm{s}$ and. $40 \mathrm{~nm}$ in the case of $\mathrm{C}_{60}$ and 0.1 and $9 \mathrm{~nm}$ for $\mathrm{Alq}_{3}$. These thicknesses have been chosen after optimisation.

After organic thin film deposition, the aluminium upper electrodes were thermally evaporated, without breaking the vacuum, through a mask with $2 \mathrm{~mm} \times 8 \mathrm{~mm}$ active area. This Al film behaves as the cathode, while the ITO is the anode. Some ITO anodes have been covered with an ultra thin metal film deposited by vacuum evaporation, the metal being $\mathrm{Au}$, $\mathrm{Cu}, \mathrm{Ni}$. The thickness of these ultra thin metal films, $\mathrm{M}$, has been varied from 0.3 to $1.2 \mathrm{~nm}$. Finally, the structures used were: glass/ITO $(100 \mathrm{~nm}) / \mathrm{M} \quad(0 \leq x \leq 1.2$ $\mathrm{nm}) / \mathrm{CuPc}(35 \mathrm{~nm}) / \mathrm{C}_{60}(40 \mathrm{~nm}) / \mathrm{Alq}_{3}(9 \mathrm{~nm}) / \mathrm{Al}(120 \mathrm{~nm})$. It can be seen in figure 18 and table 2 that the presence of the ultra-thin gold layer improves significantly the solar cells performances. When different batches of ITO were used, without Au buffer layer, the solar cells performance vary strongly, while they were of the same order of magnitude when an ultra-thin gold layer was deposited onto ITO (Table 2).

Similar results have been obtained when AZO and FTO are used. The performances of organic solar cells using this ultra thin metal layer, are nearly similar, whatever the TCO used [Bernède et al., Appl. Phys. Lett., 2008, Bernède et al., Sol. Energy Mater. Sol. Cells, 2008]. This suggests that indium free organic devices with high-efficiency can be achieved, which can contribute to the sustainable development. 


\begin{tabular}{cccccc}
\hline Batch & Anode & Jsc $\left(\mathrm{mA} / \mathrm{cm}^{2}\right)$ & Vco $(\mathrm{V})$ & FF & $\eta \%$ \\
\hline \multirow{2}{*}{$\mathrm{a}$} & $\mathrm{ITO}$ & 7.31 & 0.45 & 0.44 & 1.45 \\
& $\mathrm{ITO} / \mathrm{Au}(0.5 \mathrm{~nm})$ & 8.09 & 0.49 & 0.56 & 2.25 \\
\hline \multirow{2}{*}{$\mathrm{b}$} & $\mathrm{ITO}$ & 6.80 & 0.40 & 0.25 & 0.67 \\
& $\mathrm{ITO} / \mathrm{Au}(0.5 \mathrm{~nm})$ & 8.34 & 0.45 & 0.50 & 1.86 \\
\hline
\end{tabular}

Table 2. Photovoltaic performance data of devices achieved with batches a and b of ITO, under AM1.5 conditions.

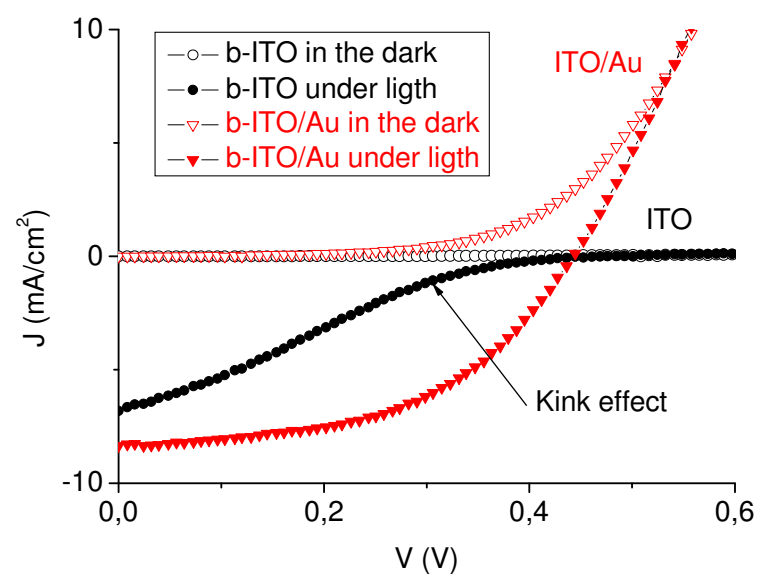

Fig. 18. Typical J-V characteristics of solar cells, with an anode of ITO (batch b) covered ( $\nabla)$ or not $(\bullet)$ with $0.5 \mathrm{~nm}$ of $\mathrm{Au}$, in the dark (open symbol) and under illumination of AM1.5 solar simulation $\left(100 \mathrm{~mW} / \mathrm{cm}^{2}\right)$ (full symbol).

As said above, others metal such as $\mathrm{Cu}, \mathrm{Ni}, \mathrm{Ag}$, $\mathrm{Pt}$ have been probed, however, up to now, the best results have been obtained with a gold ultra thin film. It should be noted that, roughly, the organic solar cells performance increases with the metal work function, which means that, Ag which have the smallest $\Phi_{\mathrm{M}}$ gives the worst performances.

In order to understand the ultra-thin gold layer effect, TCO covered with such gold layers have been characterized by scanning electron microscopy (SEM), atomic force microscope (AFP), X-ray photo-electron spectroscopy, optical transmission measurement (Figures 16, 19). It is shown that the ultra-thin film is discontinuous, while the roughness of the TCO/Au electrode is not different from that of bare TCO $(0.8 \mathrm{~nm})$. However it can be seen through the XPS study that the CuPc has grown more homogeneously when deposited onto gold covered TCO. Moreover as shown in Figure 18 the shape of the J-V characteristic depends on the anode configuration, in the case of bare TCO a "kink" effect is clearly visible, while classical diode characteristics are obtained when the TCO is covered by the ultra-thin gold layer.

In order to discuss the effect of the ultra thin gold film on solar cells performances, we recall shortly supposed beneficial effect of the classical buffer layer, the PEDOT:PSS.

As said above, up to now, the most common buffer layer inserted at this interface is the PEDOT:PSS, its contribution to the improvement of solar cells performance has been attributed to: 


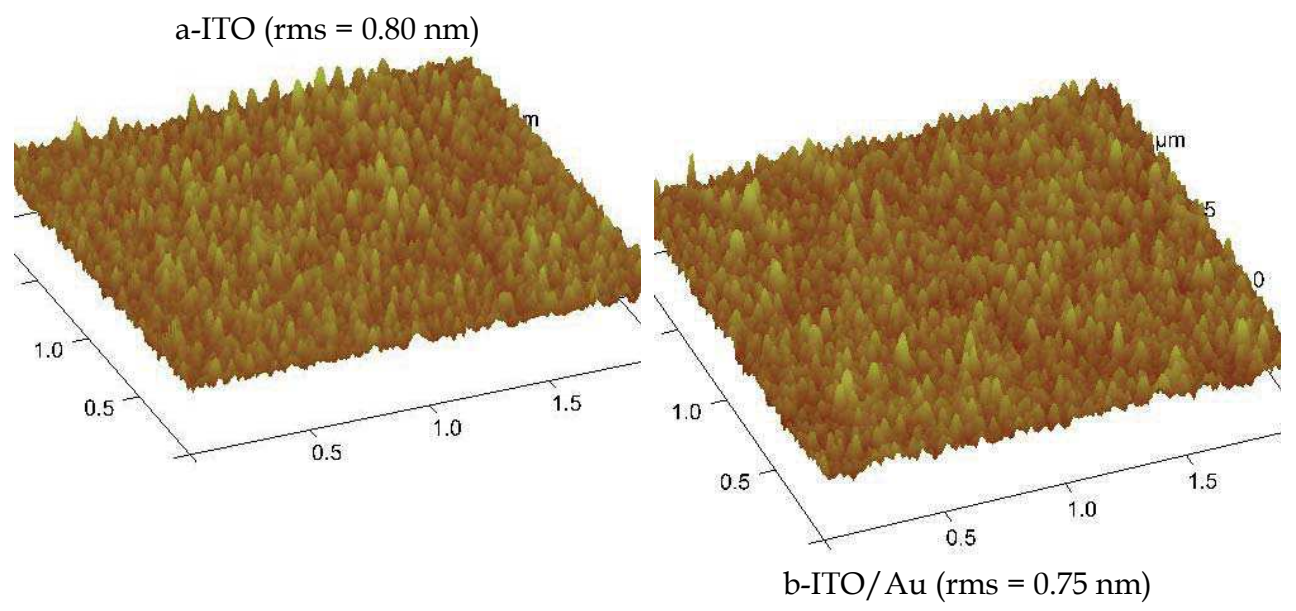

Fig. 19. AFM images of Au (0.5 nm) covered ITO (a) and bare ITO (b).

- the smoothing effect of the quite rough TCO surface, therefore, any possible short circuiting due to the spiky roughness of the TCO surface is prevented.

- the physical separation, which avoids direct contact between the oxygen of the TCO and the organic material.

- $\quad$ its work function $\left(\phi_{\mathrm{M} \text { (PEDOT: PSS })}=5.1 \mathrm{eV}\right)$, which allows to decrease the barrier height at the interface, since the work function of the TCO is smaller (4.5-4.7 eV for ITO), while the HOMO of $\mathrm{CuPc}$ is $5.2 \mathrm{eV}$.

- the improvement of the contact between the polymer and the TCO. It is admitted that this buffer layer enhances adhesion to the organic layer.

It can be seen immediately that the two first contributions can be excluded when an ultrathin gold film is substituted by PEDOT:PSS, since the roughness of the modified anode is similar to that of the initial TCO and the gold film is discontinuous. The two last contributions seem more probable. The work function of gold is $5.1 \mathrm{eV}$ and therefore the ultra-thin gold layer can improve the matching between the work function of the anode and the highest occupied molecular orbital (HOMO) of the organic electron donor (Figure 5a, b, c). Such contribution will be discussed more carefully below. The fourth contribution is in good agreement with the XPS study, which shows that the $\mathrm{CuPc}$ films are more homogeneous when deposited onto gold modified TCO.

Therefore from the examples presented above it can be concluded that the two main contributions to the interface improvement by inserting an ultra-thin metal buffer layer between the TCO anode and the $\mathrm{CuPc}$ are a better matching of the band structure (Figure 20) and a higher homogeneity of the organic film.

The equivalent circuit model (figure 5 a) could be helpful in understanding of organic solar cells by providing a quantitative estimation for losses in the cells. As said above, the equivalent circuit commonly used to interpret the I-V characteristics of real solar cells consists of a photogenerator connected in parallel with a diode and a shunt resistance, and a series resistance. For such solar cells the mathematical description of this circuit is given by the equation (1). 


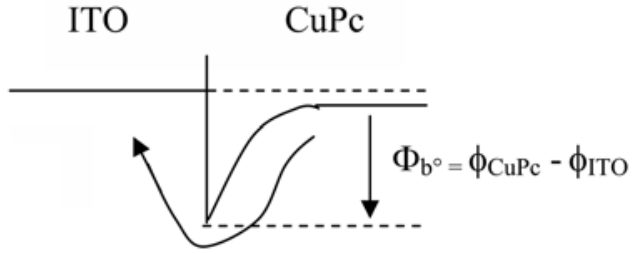

(a)
$\mathrm{TCO} \mathrm{Au} \mathrm{CuPc}$

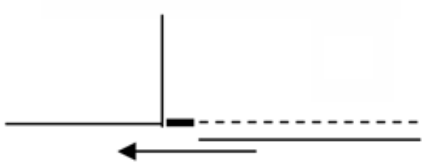

(b)

Fig. 20. Contact anode (ITO)/ electron donor (CuPc) a-without buffer layer; $b$-with a gold buffer layer.
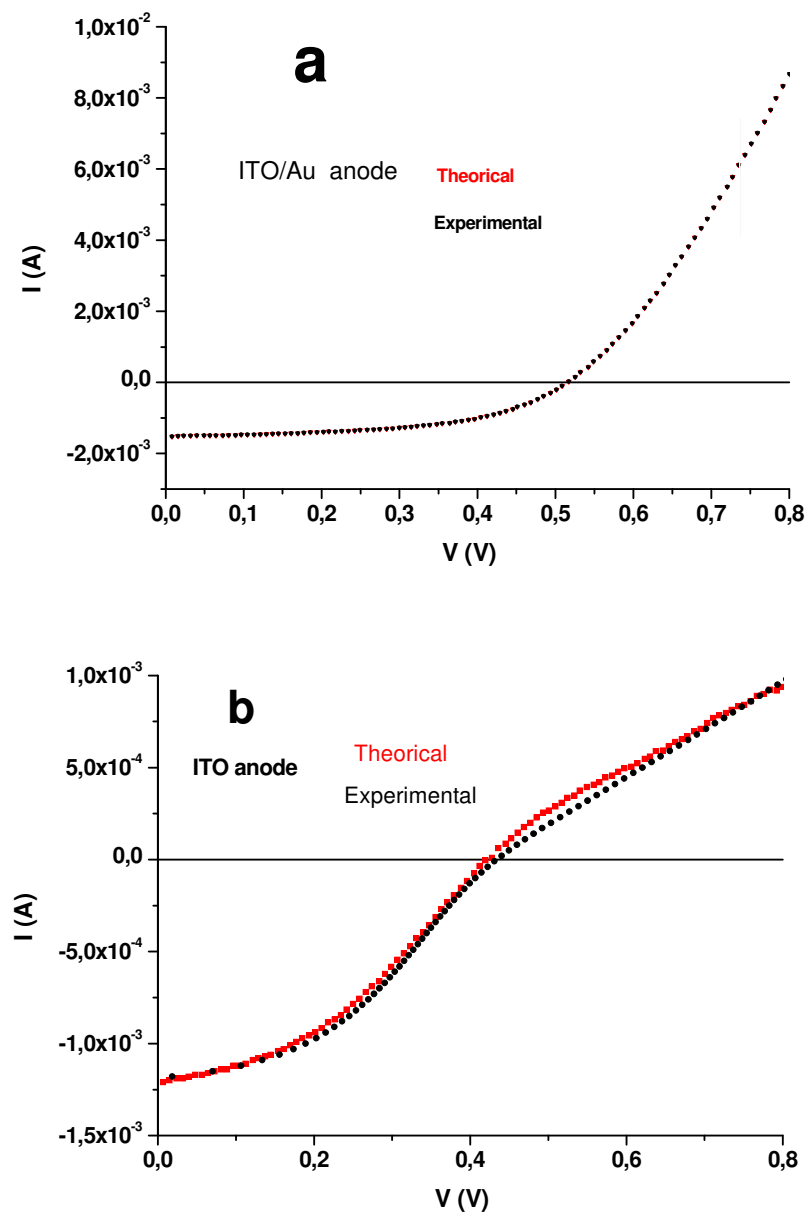

Fig. 21. I-V characteristics under AM1.5 illumination of a solar cell using a ITO/Au anode (a) and a ITO anode (b), (•) experimental and ( $\square$ ) theoretical curves. 
In a recent contribution [Kouskoussa et al., Phys. Stat. Sol. (a), 2009], we have shown that the Lambert $\mathrm{W}$-function method can be used to determinate Rs, the series resistance, Rsh the shunt resistance, $\mathrm{n}$ the ideality factor of the diode and Iph the photo-generated current.

The problem to be solved is the evaluation of a set of five parameters Rs, Rsh, n, Iph and Is in order to fit a given experimental I-Vcharacteristics using a simple diode circuit.

A good agreement between the experimental and theoretical fitted curves is achieved with ITO/ Au anode (Figure 21 a), while it is not in the case of bare ITO anode.

As said above no agreement could be achieved in the case of a bare ITO or Ag covered anode, whatever the series and shunt resistance proposed. Such impossibility shows that the simple equivalent scheme used in this theoretical study cannot explain the experimental results obtained with a bare ITO anode.

In the case of bare and Ag covered ITO anode, it is necessary to assume the presence of a back-contact barrier at the ITO/CuPc interface (figure $5 \mathrm{~b}$ ), to achieve a good fit between experimental and theoretical results. Assuming a thermoionic current at this interface, the hole current is:

$$
\mathrm{I}_{\mathrm{b}}=-\mathrm{I}_{\mathrm{b} 0}\left(\exp \left(-\mathrm{q} \mathrm{V}_{\mathrm{b}} / \mathrm{kT}\right)-1\right)
$$

With: - $\mathrm{I}_{\mathrm{b} 0}$ saturation current,

- $\mathrm{V}_{\mathrm{b}}$ voltage across the back contact,

- k Boltzmann constant,

- $\mathrm{T}$ temperature.

Therefore the current-limiting effect, "rollover", is due to the back-contact barrier height. It occurs because the total current saturate at a value $\mathrm{J}_{\mathrm{b} 0}$ [Demtsu and Sites, Thin Solid Films, 2006]. The value of $\mathrm{J}_{\mathrm{b} 0}$ is the current value where the $\mathrm{J}-\mathrm{V}$ curve starts to show rollover.

Demtsu and Sites have treated the main junction and the back-contact junction (Figure $6 \mathrm{~b}$ ) as independent circuit element. Here, when a forward bias $\mathrm{V}$ is applied to the circuit, the voltage is divided between $\mathrm{V}_{\mathrm{m}}$ across the main $\mathrm{CuPc} / \mathrm{C}_{60}$ junction, $\mathrm{V}_{\mathrm{b}}$ across the backjunction TCO/CuPc and IRs across the series resistance:

$$
\mathrm{V}=\mathrm{V}_{\mathrm{m}}+\mathrm{V}_{\mathrm{b}}+\mathrm{IRs} .
$$

Under illumination the current across the main junction is:

$$
I_{m}=I_{m 0}\left(\exp \left(q V_{m} / n k T\right)-1\right)-I p h+V m / R s h
$$

And through the back contact it is:

$$
I_{b}=-I_{b 0}\left(\exp \left(-q V_{b} / k T\right)-1\right)+V b / R^{b h}
$$

Equating equations (10) and (11):

$$
I_{m 0}\left(\exp \left(q V_{m} / n k T\right)-1\right)-I p h+V m / R s h+I_{b 0}\left(\exp \left(-q V_{b} / k T\right)-1\right)-V b / R_{s h}{ }_{s h}=0
$$

The parameters Rs and $\mathrm{I}_{\mathrm{m} 0}, \mathrm{n}$, Rsh of the main diode are calculated in the region far from the saturation current $\mathrm{Ib}$. As said above, $\mathrm{I}_{\mathrm{b} 0}$ is the current value where the $\mathrm{J}-\mathrm{V}$ curve starts to show rollover. Then equation (13) can be solved.

A good agreement can be achieved between experimental and theoretical curves, (Figure 21 b), which validates the hypothesis of the presence of a rectifying effect at the ITO/CuPc contact. 
The parameters extracted are reported in Table 3. It should be noted that when ITO is covered with Ag, two diodes are necessary to obtain a good fit between the experimental and theoretical curves. Since the work function of $\mathrm{Ag}$ is only $4.3 \mathrm{eV}$, this result is in good agreement with the present discussion. One can see in Table 3 that, when the two diodes model is used, the estimated Rs values are of the same order of magnitude as those of ITO/Au anode. Therefore the introduction of a back junction diode is a good interpretation of the interface ITO/CuPc. It justifies the small fill factor and short circuit current values when bare ITO is used as anode in the heterojunction solar cells. The Voc value can be improved thought an increase of the shunt resistance value. It can be seen in Table 3 that the shunt resistance value of the cells with a ITO/ Au anode is significantly higher.

\begin{tabular}{ccccccc}
\hline Anode & \multicolumn{3}{c}{ Main junction CuPc/C 60} & \multicolumn{3}{c}{ Back-contact junction } \\
& $\mathrm{n}$ & Rsh & Rs & $\mathrm{I}_{\mathrm{mo}}(\mathrm{A})$ & $\left.\mathrm{R}_{\mathrm{sh}}(\Omega)\right)$ & $\mathrm{I}_{\mathrm{bo}}(\mathrm{A})$ \\
\hline $\mathrm{ITO}$ & 2.55 & 330 & 20 & $210^{-6}$ & 15000 & $2.5810^{-6}$ \\
$\mathrm{ITO} / \mathrm{Ag}$ & 2.6 & 400 & 40 & $110^{-6}$ & 13200 & $2.2410^{-6}$ \\
\hline $\mathrm{ITO} / \mathrm{Au}$ & 1.5 & 6900 & 25 & $2.2310^{-9}$ & - & - \\
\hline
\end{tabular}

Table 3. Parameters calculated using a main diode and (or not) a back contact diode.

Table 3 shows that the ideality factor, n, decreases, while Rsh increases, when the ITO anode is covered by an ultra-thin Au layer, which corresponds to a significant improvement of cell performance. When Ag is used the improvement is not significant. The increase of Rsh can be related to the growth of pinhole free organic films when deposited onto Au coated TCO [Kim et al., Sol. Energy Mater. Sol. Cells, 2009].

When thicker metal films are introduced at the anode/organic interface, surface plasmon effect has been proposed as alternative approach toward enhanced light absorption without the need for thick films. [Chen, et al., Appl. Phys. Lett., 2009]. A surface plasmon is an optically generated wave, which propagates along a metal/dielectric interface. In tuning the light excitation, a resonance can occur when the frequency of the incident photon equals the collective oscillation frequency of conduction electrons of metallic particles. These properties can be used in the photovoltaic domain in order to improve the light absorption. Theoretical calculations have been performed to determine optimal plasmonic materials to optimise light absorption [Duche, et al. Sol. Energy Mater. Sol. Cells, 2009]. Enhanced absorbance up to $50 \%$ has been experimentally obtained in a $50 \mathrm{~nm}$ thick blend film including silver nanospheres with a diameter of $40 \mathrm{~nm}$. Devices based on BHJ structures using ITO anode covered with Ag nanodots permits 20\% improvement of the efficiency [Kim et al., Appl. Phys. Lett., 2008]. The plasmon resonance wavelength depends on the metal nanodots properties, it can be tuned by annealing the silver film or using other metal [Morfa,. Appl. Phys. Lett., 2008]. Even if the efficiency of the surface plasmon effect in the field of solar cells is always under discussion, it is often proposed to improve the light absorption.

After metals, different oxides $\left(\mathrm{MoO}_{3}, \mathrm{WO}_{3}, \mathrm{ZnO}\right)$ have been probed as buffer layer at the TCO anode / CuPc interface.

In the case of OLEDs [Im et al., Thin Solid Film, 2007; Hsu \& Wu, Appl. Phys. Lett., 2004; Shi, Ma, and Peng, Eur. Phys. J. Appl. Phys., 2007; Qiu et al., J. Appl. Phys., 2003;

Matsushima et al., Appl. Phys. Lett., 2007; Jiang et al., J. Phys. D: Appl. Phys., 2007; You et al., J. Appl. Phys., 2007] and organic thin film transistors [Chu et al., Appl. Phys. Lett., 2005;

Park, Noh and Lee, Appl. Phys. Lett., 2006], different attempts have been done, with some success, using different oxide thin films as buffer layer between the TCO and the organic 
material. Also some attempts have been probed in the case of organic solar cells [Yoo et al., Synthetic Metals, 2005; Chan et al., J. Appl. Phys., 2006]. The use of such buffer layer is based on the idea that the potential barrier at the ITO/organic donor interface can be reduced by elevation of ITO surface work function, giving high hole transport at this interface. In order to check this hypothesis, using the same multiheterojunctions as above, we have probed different buffer layers at the ITO/CuPc interface. The buffer layers used were $\mathrm{MoO}_{3}, \mathrm{WO}_{3}$ and $\mathrm{ZnO}$. The resulting different $\mathrm{I}-\mathrm{V}$ characteristics are compared to those of a reference cell built on untreated anode. The different energy band diagrams are proposed and discussed. Finally, we demonstrate that the reduction process of the barrier at the ITO/organic donor interface depends on the type of material: oxide or metal.

During this study, the majority of the ITO anodes have been covered with an oxide buffer layer. These thin buffer layers were deposited by vacuum evaporation. The $\mathrm{MoO}_{3}$ oxide thin films were thermally evaporated onto the ITO coated glass. The thickness of these ultra thin oxide films ranged between 1 and 7 .

Finally, the structures used were: glass /ITO(100nm)/bufferlayer/CuPc $(40 \mathrm{~nm}) / \mathrm{C}_{60}(40 \mathrm{~nm}) / \mathrm{Alq}_{3}(9 \mathrm{~nm}) / \mathrm{Al}(120 \mathrm{~nm}) / \mathrm{P}_{\mathrm{Se}}$.

The optimum efficiencies were achieved for thickness of around $3.5 \pm 1 \mathrm{~nm}$, that means that, as in the case of gold, the oxide film does not completely cover the anode surface since it has been shown that $5 \mathrm{~nm}$ are necessary to obtain continuous thin $\mathrm{MoO}_{3}$ film, using thermal evaporation [Song et al., Chem. Phys. Lett.,2005]. For thicker oxide films, if the fill factor (FF) stays far higher than the value obtained with bare ITO, the short circuit current (Jsc) is slightly smaller and it progressively decreases as the oxide thickness increases. With thinner oxide films the inflection point, in the J-V characteristics, typical of the bare ITO anode (Figure 22), is still slightly present.

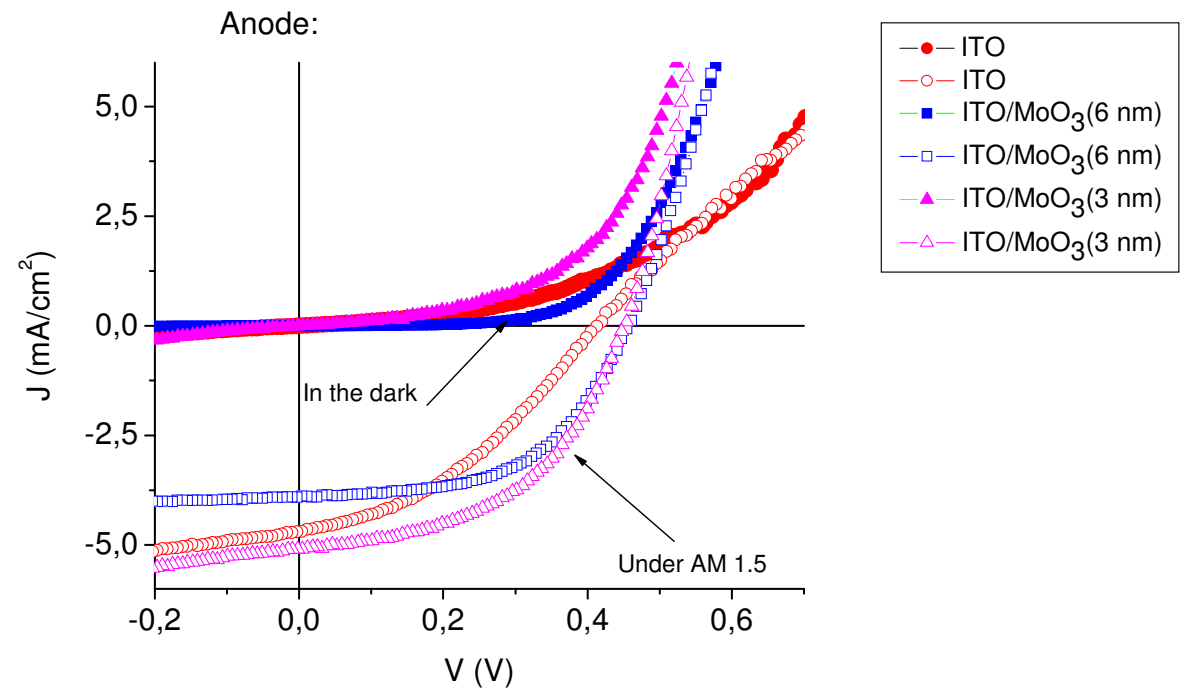

Fig. 22. Typical J-V characteristics of Anode $/ \mathrm{CuPc}_{\mathrm{C}} / \mathrm{C}_{60} / \mathrm{Alq}_{3} / \mathrm{Al}$ structure, with Anode $=$ ITO $(\bullet)$, ITO/ $\mathrm{MoO}_{3}(6 \mathrm{~nm})(\bullet)$ and ITO/ $\mathrm{MoO}_{3}(3 \mathrm{~nm})(\boldsymbol{\Delta})$, in the dark (full symbol) and under illumination of AM1.5 solar simulation $\left(100 \mathrm{~mW} / \mathrm{cm}^{2}\right)$ (open symbol). 
It should be highlighted that the main improvement induced by the oxide is related to the fill factor (Table 4). Here also the improvement induced by the oxide does not depend on the TCO used, since the best result achieved by the cells deposited during the run corresponds to FTO. Here also the presence, or not, of the kink effect testifies of the efficiency of oxide.

A similar approach to the one used in the case of gold buffer layer can be used in the case of oxide buffer layer. Often the positive effect on the properties of the organic optoelectronic devices of the anode buffer layer is mainly attributed to the reduction of the barrier energy between the ITO, which is usually the anode, and the organic layer (electron donor for solar cells, hole transporting layer for OLEDs...).

\begin{tabular}{cccc}
\hline Anode & $\mathrm{ITO}$ & $\mathrm{ITO} / \mathrm{MoO}_{3}(6 \mathrm{~nm})$ & $\mathrm{ITO} / \mathrm{MoO}_{3}(3 \mathrm{~nm})$ \\
\hline $\mathrm{Jsc}\left(\mathrm{mA} / \mathrm{cm}^{2}\right)$ & 4.69 & 3.90 & 5.05 \\
\hline $\mathrm{Voc}(\mathrm{V})$ & 0.41 & 0.46 & 0.45 \\
\hline$\eta(\%)$ & 0.73 & 0.97 & 1.13 \\
\hline $\mathrm{FF}(\%)$ & 38 & 54 & 49.7 \\
\hline
\end{tabular}

Table 4. Photovoltaic performance data under AM1.5 conditions of devices using ITO, $\mathrm{ITO} / \mathrm{MoO}_{3}(3 \mathrm{~nm})$ and $\mathrm{ITO} / \mathrm{MoO}_{3}(6 \mathrm{~nm})$ anodes.

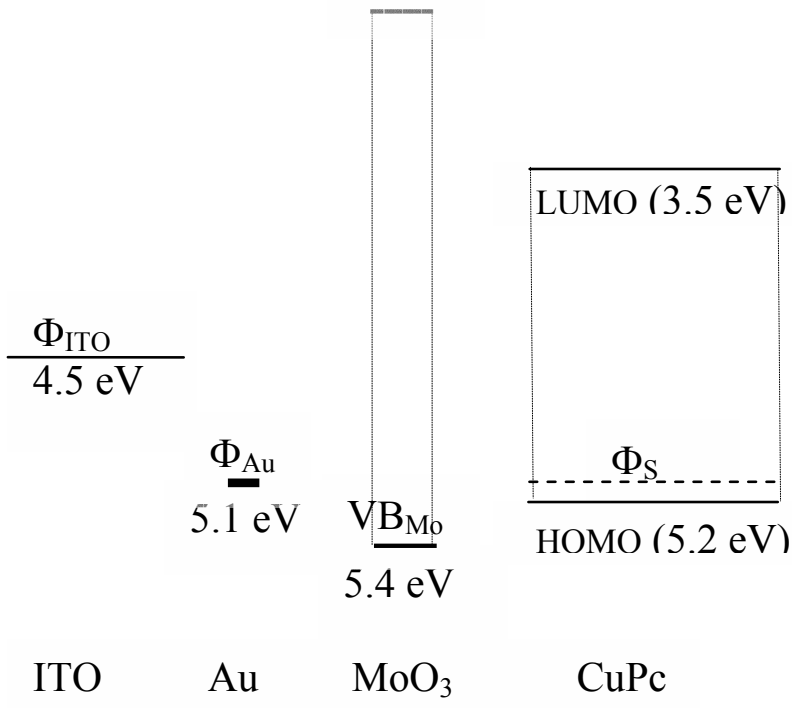

Fig. 23. Band scheme before contact

If the buffer layer material exhibits a high work function value (Figure 23), i.e., a work function in good agreement with the HOMO of the organic layer, it is often suggested that there is a simple alignment of the energetic levels of the anode and the organic material, without any discussion of the electrical properties of the buffer layer. However the electrical behavior of conductive, semi conducting and insulating materials is very different and therefore the nature of their interfaces will depend on the their properties. 
If we introduce an insulating film, (I), between the metal, (M) (or degenerated semiconductor), and the semiconductor, (S), the contact behaves like a MIS structure. This means that there is not band alignment between the TCO, the insulating layer and the organic semiconductor but, qualitatively, the band diagram of Figure 24. This results from the fact that the Fermi level must be constant throughout the metal/insulating layer/semiconductor and therefore [Demtsu et Sites, Thin Solid Films, 2006]:

$$
\Phi_{\mathrm{b}^{\circ}}=\Phi_{\mathrm{b}}+\Delta
$$

The distribution between $\Phi_{\mathrm{b}}$ and $\Delta$ depends on the insulating properties of the oxide and the semiconductor properties. The space charge, which forms in the depletion layer of the semiconductor, can be expressed as an equivalent surface state density Qsc. In the ideal case, that is to say in the absence of any space charge effect in the interfacial insulating layer, an exactly equal and opposite charge Qm develops on the metal surface. In this case of an ideal insulating layer the potential $\Delta$ across the interfacial layer can be obtained, following the application of Gauss law to the surface charge on the metal and semiconductor:

$$
\Delta=\delta\left(\mathrm{Qm} / \varepsilon_{\mathrm{i}}\right)
$$

$\varepsilon_{\mathrm{i}}$ being the dielectric constant of the insulating layer and $\delta$ its thickness [Sze, Physics of Semiconductor Devices, John Wiley Editor, 1981]. Therefore, even if there is not a simple alignment of the work function of the insulating film with those of the conductive anode and of the semiconductor, the presence of this layer can significantly modifies the barrier value at the interface through the potential $\Delta$ [Park, Noh and Lee, Appl. Phys. Lett, 2006]. As a summary, in the case of the present work, since we have (Figure 23): $\Phi_{\mathrm{ITO}}=4.5 \mathrm{eV}, \Phi_{\mathrm{Au}}=$ $5.1 \mathrm{eV}, \mathrm{HOMO}_{\mathrm{CuPc}}=5.2 \mathrm{eV}, \mathrm{VB}_{\mathrm{MoO} 3}=5.4 \mathrm{eV}$.

- the ITO/CuPc contact induces a pseudo Schottky contact, $\mathrm{V}_{\mathrm{bi}}=\phi_{\mathrm{M}}-\phi_{\mathrm{S}}$ between 0.5 and $0.7 \mathrm{eV}, \mathrm{CuPc}$ being an electron donor (p-type semiconductor), $\phi$ s is slightly smaller than $\mathrm{HOMO}_{\mathrm{CuPc}}$ (Figure $20 \mathrm{a}$ ), while the $\mathrm{Au} / \mathrm{CuPc}$, and therefore ITO/Au/CuPc, contacts induce a nearly ohmic contact (Figure $20 \mathrm{~b}$ ).

- the ITO $/ \mathrm{MoO}_{3} / \mathrm{CuPc}$ behaves like a MIS structure, that is to say the insulating layer induces a decrease of the barrier height with $\Phi_{\mathrm{b}}=\Phi_{\mathrm{b}^{\circ}}-\Delta$ [ Cowley and Sze, J. Appl. Phys., 1965]. As discussed above the efficiency of the insulating layer in the band alignment depends on the insulating properties and the thickness of the $\mathrm{MoO}_{3}$ layer (Figure 24).

We have now all the keys necessary to explain the behaviour of the different cells studied in the present work. It is well known that a barrier is present at the interface ITO/organic material (electron donor in the case of solar cells and hole transporting layer in the case of OLEDs). The introduction of an interfacial layer between the ITO and the organic material allows to decrease the barrier height at the interface, which facilitate the hole collection (solar cells) or hole injection (OLEDs). It is clear from the discussion above that an oxide or a metal with sufficiently high work function value should be used.

$\mathrm{MoO}_{3}$ has already been used to increase the hole injection in OLEDs [Matsushima et al., Appl. Phys. Lett., 2007; Jiang et al., J. Phys. D: Appl. Phys., 2007]. The decrease in the barrier height, allowed by the introduction of $\mathrm{MoO}_{3}$ layer, increases with its thickness (equation 16). However, as shown by the experimental study, there is an optimum thickness value. 
When the film is too thin $(\leq 1.5 \mathrm{~nm})$ the $\Delta$ value is small and moreover the covering efficiency of the ITO by the $\mathrm{MoO}_{3}$ is not complete. For $\mathrm{MoO}_{3}$ layers thicker than $6 \mathrm{~nm}$, the short circuit current significantly decreases (Figure 22).

In Figure 24 it is supposed that the carriers cross the insulating layer by tunnel effect. The interfacial buffer layer is assumed to be a few angstroms thick and transparent to carriers whose energy is greater than the potential barrier of the semiconductor. However, when the thickness of the insulating layer increases, the probability of tunnel effect decreases. It is admitted that up to $3 \mathrm{~nm}$ the efficiency of the tunnel effect is maximum, while it decreases progressively for thicker films.

We have shown that the optimum $\mathrm{MoO}_{3}$ thickness is around $3.5 \pm 1 \mathrm{~nm}$, which means that the insulating layer is efficient even for thickness higher than the theoretical optimum value. However evaporated molybdenum oxide films are strongly oxygen deficient and Rozzi et al have shown, in a theoretical study, that, when some oxygen is removed from the $\mathrm{MoO}_{3}$ crystal, some Mo4d antibonding orbitals located in the gap are filled up [Rozzi et al., Phys. Rev., 2003]. Therefore holes can cross the insulating film by multiple tunnelling steps [A.G. Milnes, D.L. Feucht, "Heterojunctions and metal semi-conductor junctions.", Academic Press Editor, 1972.] effect through these gap states introduced by the oxygen vacancies. As a result, the probability of tunnelling though the barrier increases. Finally the optimum $\mathrm{MoO}_{3}$ thin film thickness, $3.5 \pm 1 \mathrm{~nm}$, corresponds to a compromise between an optimum ITO coverage and a sufficient transparency to charge carriers.

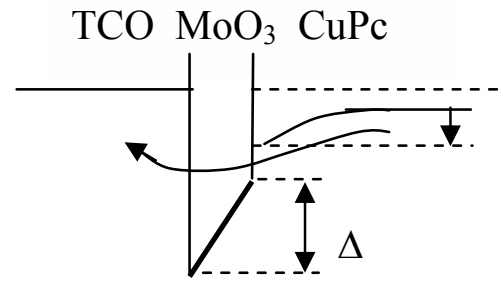

Fig. 24. Band scheme after contact: Hole transfer from the organic electron donor to the anode for different anode configurations after contact.

\section{Example of the effect of an organic buffer layer used in different configurations}

Factors which limit organic solar cells performance include limited spectral sensitivity, carriers separation at the interface acceptor/donor, low carrier mobility, energy step at the organic material/electrode. In devices based on ED/EA heterojunction, the theoretically obtainable open circuit potential (Voc) is given by the difference between the highest occupied molecular orbital of the electron donor $\left(\mathrm{HOMO}_{\mathrm{D}}\right)$ and the lowest unoccupied molecular orbital of the electron acceptor $\left(\mathrm{LUMO}_{\mathrm{A}}\right): \Delta\left(\mathrm{HOMO} \mathrm{D}_{\mathrm{D}}-\mathrm{LUO}_{\mathrm{A}}\right)$ [Zimmermann et al., Thin Solid Films 2005]. The introduction, at the electron donor /electron acceptor interface, of an ultra-thin organic layer could allows controlling the Voc value by modifying this difference as shown by Kinoshita and col. [Kinoshita et al., Appl. Phys. Lett., 2007]. They use with success this multicharge separation interface concept to increase the Voc value. They introduce an ultra-thin CuPc layer, which is usually used as electron donor, at the pentacene/fullerene interface. CuPc has also been proved to be an efficient buffer 
layer [Hong, Huang, and Zeng, Chem. Phys. Lett., 2006]. In order to improve carrier mobility, structural templating of $\mathrm{CuPc}$ has been obtained using an ultra-thin 3,4,9,10perylenetetracarboxyl dianhydride interlayer [Sullivan, Jones and Ferguson, Appl. Phys. Lett., 2007]. In the present example, similar experiments have been done with a perylene derivative:N, $\mathrm{N}^{\prime}$-diheptyl-3,4,9,10-perylenebiscarboximide (PTCDI-C7).

\subsection{Synthesis of the N,N'-diheptyl-3,4,9,10-perylenebiscarboximide (PTCDI-C7)}

PTCDI-C7 (Figure 25) was synthesized by condensation of PTCDA with heptylamine [Demmig and Langhals, Chem. Ber., 1988]. This compound is sufficiently soluble in chloroform to allow a chromatographic method for purification. Yield: $85 \%$. The elemental microanalyses results are in good agreement with the expected ones (weight \%: $\mathrm{C}=77.76 ; \mathrm{H}$ $=6.74 ; \mathrm{N}=5.11$ ).

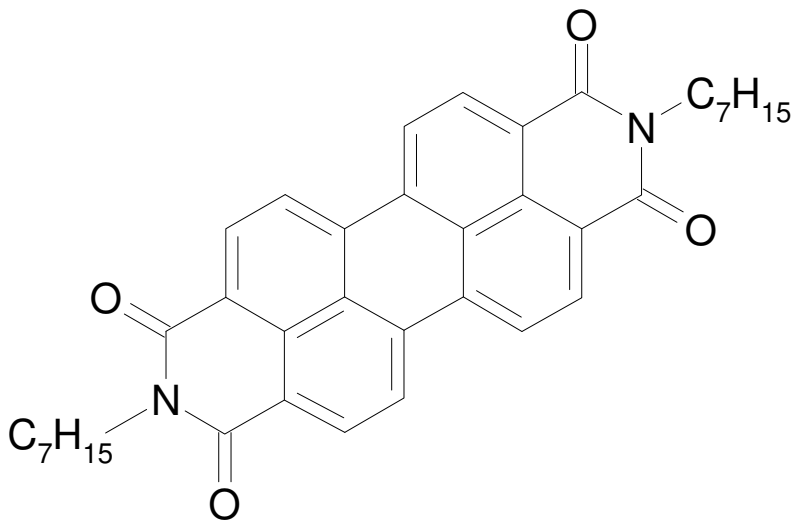

Fig. 25. PTCDI-C7 molecule.

\subsection{Organic solar cells realisation}

In the present series of experiments, the TCO electrode was a layer of indium tin oxide (ITO) on glass substrate. CuPc, PTCDI-C7, $\mathrm{C}_{60}$ and $\mathrm{Alq}_{3}$ have been deposited in a vacuum of $10^{-4}$ $\mathrm{Pa}$. The thin film deposition rate and thickness were estimated in situ with a quartz monitor. The deposition rate and final thickness were $0.05 \mathrm{~nm} / \mathrm{s}, 35 \mathrm{~nm}$ for CuPc, $0.05 \mathrm{~nm} / \mathrm{s}$ and 40 $\mathrm{nm}$ in the case of PTCDI-C7 and or $\mathrm{C}_{60}$ and $0.05 \mathrm{~nm} / \mathrm{s}$ and $8 \mathrm{~nm}$ for $\mathrm{Alq}_{3}$. The thicknesses have been chosen after optimisation.

We have shown earlier that the presence of an ultra-thin metallic film at the TCO/organic material interface allows improving significantly the power conversion efficiency of organic solar cells [Bernède et al., Appl. Phys. Lett., 2008]. So, a very thin Au film (0.5 nm) has been introduced at the interface ITO/CuPc in the most cases. The thickness of the organic films has been checked with a scanning electron microscope (SEM). After organic thin film deposition, aluminium upper electrodes were thermally evaporated (150 nm thick), without breaking the vacuum, through a mask with $1.5 \mathrm{~mm} \times 6 \mathrm{~mm}$ active area.

\subsection{Experimental tests and discussion of the effect of PTCDI-C7 buffer layers}

As justified above, PTCDI-C7 has been probed as a buffer layer at the $\mathrm{CuPc}_{\mathrm{P}} / \mathrm{C}_{60}$ and anode/electron donor interfaces. Following the multicharge separation interfaces concept, 
in order to improve Voc, an ultra-thin PTCDI-C7 has been introduced at the heterojunction $\mathrm{CuPc} / \mathrm{C}_{60}$ interface. The PTCDI-C7 thickness was $4 \mathrm{~nm}$. However, while there was a strong decrease of the short circuit current Jsc, there was not any Voc increase (Figure 26). It has already been shown [Zhou et al., Sol. Energy Mater. Sol. Cells, 2007] that, in the case of bulkheterojunctions, charge separation yield achieved with perylene derivatives is smaller than the one achieved with $\mathrm{C}_{60}$. The same effect can explain the strong Jsc decrease in the presence of PTCDI-C7 at the $\mathrm{CuPc} / \mathrm{C}_{60}$ interface.
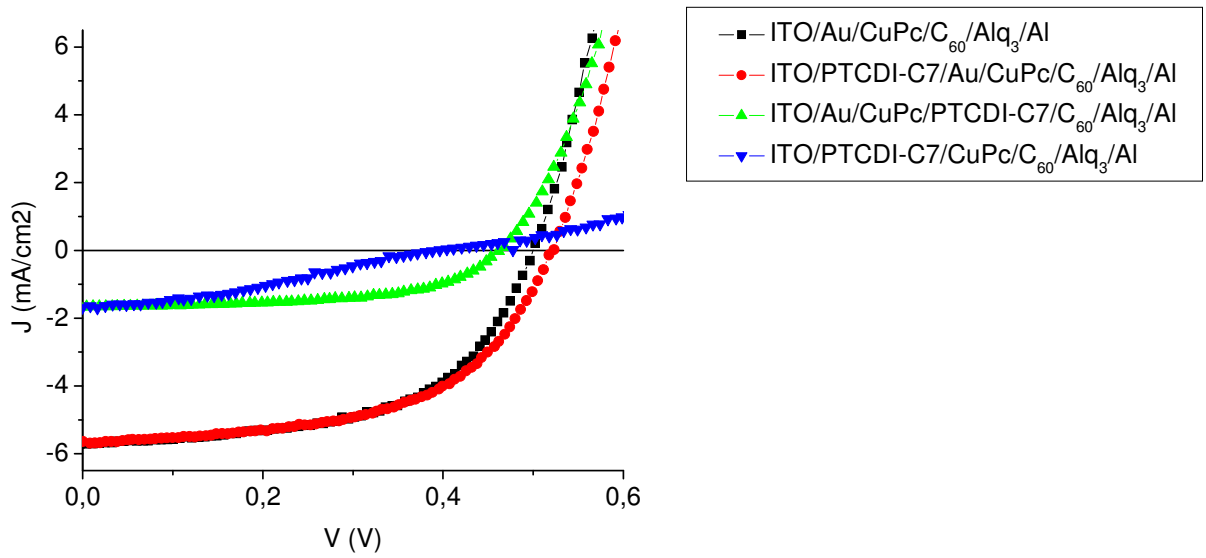

Fig. 26. Typical J-V characteristics under illumination of AM1.5 solar simulation (100 $\mathrm{mW} / \mathrm{cm}^{2}$ ) with different anodes.

Then PTCDI-C7 has been probed as buffer layer at the anode/electron donor interface. A thin PTCDI-C7 ultra-thin layer has been introduced at the anode/CuPc interface. The results are summarized in Figure 26 and table 5. It can be seen that, if, as expected, the presence of $\mathrm{Au}$ improves significantly the devices performances, it is not the case when PTCDI-C7 is substituted to Au. However, when a PTCDI-C7 ultra-thin film $(0.2 \mathrm{~nm})$ is deposited onto ITO and then covered with $\mathrm{Au}(0.5 \mathrm{~nm})$ there is a significant increase of Voc. Such increase is reproducible. A systematic study of the thickness of this buffer layer has shown that $0.2 \mathrm{~nm}$ is the optimum value, for thicker PTCDI-C7 film there is a fast decrease of Jsc, FF and therefore of the efficiency of the cells (Table 5).

\begin{tabular}{cccccccc}
\hline Au thickness $(\mathrm{nm})$ & 0.5 & 0.5 & 0.5 & 0.5 & 0.5 & 0 & 0 \\
\hline $\begin{array}{c}\text { PTCDI-C7 thickness } \\
(\mathrm{nm})\end{array}$ & 0 & 1 & 2 & 3 & 4 & 2 & 0 \\
\hline Voc $(\mathrm{V})$ & 0.50 & 0.50 & 0.52 & 0.48 & 0.47 & 0.1 & 0.44 \\
\hline Jsc $\left(\mathrm{mA} / \mathrm{cm}^{2}\right)$ & 5.63 & 5.62 & 5.64 & 3.75 & 2.88 & 0.35 & 3.21 \\
\hline FF $\%$ & 57 & 56 & 56 & 34 & 26 & 22 & 0.24 \\
\hline$\eta \%$ & 1.60 & 1.58 & 1.63 & 0.61 & 0.35 & 0.008 & 0.33 \\
\hline
\end{tabular}

Table 5. Photovoltaic characteristics, under light AM1.5 $\left(100 \mathrm{mWcm}^{-2}\right)$, for different cells using PTCDI-C7 as buffer layer deposited onto the ITO 
Sullivan and col. [Sullivan, Jones and Ferguson, Appl. Phys. Lett., 2007] have shown that, in the case of PTCDA buffer layer, there is some structural templating of CuPc which results in a higher carrier mobility and therefore Jsc increase. It can be observed in Figure 27, that the CuPc film grown on PTCDI-C7 exhibits a slightly higher ordering than those grown onto ITO or ITO/Au. The tendency of CuPc to grow with higher degree of order is expected to improve the carrier mobility in the films.

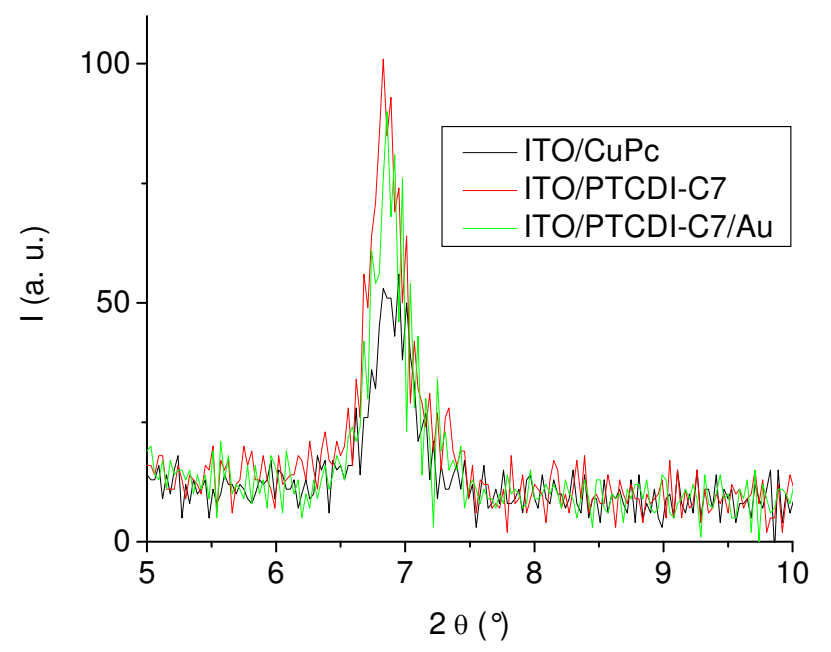

Fig. 27. Difractograms of CuPc thin films, $35 \mathrm{~nm}$ thick, deposited onto different cathodes

However, in our study, the more significant effect of the PTCDI-C7 buffer layer is not an increase of Jsc but of Voc. Probably, since the presence of the PTCDI-C7 buffer layer induces higher degree of order of CuPC films it should avoid the presence of pinholes and other defects growth, which increases the shunt resistance value of the solar cells. We have already shown that such diode improvement allows increasing the Voc value [Karst and Bernède, Phys. Stat Sol. (a), 2006]. The study of the PTCDI-C7 films has shown that it has small conductivity. When the film thickness is only $2 \mathrm{~nm}$, the carriers can cross the buffer layer by tunnel effect and the photocurrent is not decreased, for thicker buffer layer, the tunnel effect efficiency decreases and does the current.

In conclusion, the example of PTCDI-C7 developed above is a good illustration of the very broad possibility of original buffer layers. Here, a first gold buffer layer allows, as shown above to improve significantly the solar cells performances mainly through a decrease of the barrier height at the interface organic donor/TCO anode. Besides, the gold buffer layer increases the shunt resistance by decreasing the density of pinholes present in the CuPc films. We have shown here that this last effect could be improved by inserting a thin PTCDI$\mathrm{C} 7$ at the interface just onto the TCO. This layer induces structural templating of $\mathrm{CuPc}$ as shown by the XRD study. Therefore, while PTCDI-C7 is clearly not an ideal surface modification of the anode in term of energy level alignment for hole collection (cf 4.3), the effect of shunt resistance increase allows improving the open circuit voltage. 


\section{Conclusion, toward the future.}

In the last 22 years that have elapsed since the pioneering work of Tang [Tang, Appl. Phys. Lett., 1986], significant improvement in the fundamental understanding and cells construction have led to efficiencies higher than $6 \%$. The new concept of polymer:fullerene $\mathrm{BHJ}$ solar cells has allowed dramatic improvements in devices efficiency. It has induced a healthy competition with the multi-heterojunction devices base on small organic molecules, which induces significant progress in both cells families. A common aspect of both families is the great difficulty to control the electrode/organic material interface. This aspect is largely developed in the present work. One key issue for organic optoelectronic is the understanding of the energy-level alignment at organic material/electrode interfaces and the knowledge of the influence of the bottom electrode on the structural properties of the organic films. Even if not easy to predict, since dipole effect related to different possible origin are often present, the behaviour of an electrode/organic material contact can be roughly estimated using quite classical theory such as the Schottky-Mott model. Therefore the knowledge of the HOMO and LUMO values of the organic materials and that of the work functions of the electrodes are very helpful in the choice of new materials and structures configuration.

The challenges for the next organic solar cells improvements focus not only on new efficient absorbing organic materials, but developing new buffer layers, new cells architecture, new transparent conductive electrodes....

In the case of $\mathrm{BHJ}$ devices, the use of a $\mathrm{TiO}_{x}$ buffer layer inserted between the blend and the cathode gives considerable enhancement in the photocurrent attributed to the optical spacer effect of the $\mathrm{TiO}_{x}$ film [Kim et al., Adv. Mater., 2006]. In the same order of idea, as discussed above, the introduction of an ultra-thin gold film $\left(0.5 \mathrm{~nm}\right.$ ) (or a $3 \mathrm{~nm}$ thick $\mathrm{MoO}_{3}$ film) at the anode/electron donor interface, allows strong solar cells improvement, whatever the transparent conductive oxide used, which demonstrates that well fitted buffer layer could allow in the new future to grow organic solar cells indium free.

The extent to which subtle interfacial buffer layers modification can change devices performance indicates that much room exists for improvement of organic solar cells.

Nowadays, two manufacturing techniques are mainly used, vacuum processing for the small organic molecules and wet processing for the polymers. In a first approach, wet processing, if transposable to simple ink jet process, has the advantage of low cost technique, however vacuum processing presents the advantages of easy fabrication of high quality thin films from highly purified materials, well controlled films thickness and therefore simplicity to construct complex multilayers structures. Even if, in a first approach, vacuum process appears more costly, its reproducibility can made it competitive for large scale massive production.

A cost factor of both cell families is oxygen and water protection. To day packaging is obtained using additive multilayer structures [Kim et al. Appl. Phys. Lett. (2009)], However, packaging techniques must be compatible with the substrate, which could be flexible, the active material and the final cost of the panel. One possible opportunity could be to use buffer layer which gives devices not only with high efficiency but also with long life structures.

The future of organic solar cells is bounded to the concept of "electronics everywhere", where light and flexible devices such as organic solar cells could play a major role in combination with thin films batteries... 


\section{References}

T.D. Anthopoulos, B. Singh, N. Marjanovic, N.S. Sariciftci (2006). High performance nchannel organic field-effect transistors and ring oscillators based on $\mathrm{C}_{60}$ fullerene films, Appl. Phys. Lett., 89, 213504.

N.R. Armstrong, C. Carter, C. Donley, A. Simmonds, P. Lee, M. Brumbach, B. Kippelen, B. Domercq, S. Yoo, (2003). Interface modification of ITO thin films: organic photovoltaic cells, Thin Solid Films, 445, 342-352.

M.A. Baldo, S.R. Forrest, (2001). Interface-limited injection in amorphous organic semiconductors, Phys. Rev. B 64, 085201.

A. J. Bard, L. R. Faulkner (1984). Electrochemical Methods. Fundamentals and Applications, Wiley, New York, p 634.

J.C Bernède, L. Cattin, M. Morsli, Y. Berredjem (2008). Ultra thin metal layer passivation of the transparent conductive anode in organic solar cells. Solar Energy Materials and Solar Cells, 92, 1508-1515.

J. C. Bernède, V. Jousseaume, M. A. Del Valle, F. R. Diaz (2001), Current Trends in polymer Sciences, From the organic electroluminescent diodes to the new organic photovoltaic cells, Vol 6, pp.135-155.

J.C. Bernede, Y. Berredjem, L. Cattin, M. Morsli (2008). Improvement of organic solar cells performances using a zinc oxide anode coated by an ultra thin metallic layer. Appl. Phys. Lett., 92, 083304.

Y. Berredjem, J.C. Bernede, S. Ouro Djobo, L. Cattin, M. Morsli, A. Boulmokh (2008). On the improvement of the efficiency of organic photovoltaic cells by the presence of an ultra-thin metal layer at the interface organic/ITO. The European Physical Journal: Applied Physics, 44, 223-228.

Y. Berredjem, N. Karst, A. Boulmokh, A. Drici, J.C. Bernede (2007) Optimisation of the interface "organic material/aluminium" of $\mathrm{CuPc} / \mathrm{C}_{60}$ based photovoltaic cells, the European Physical Journal: Applied Physics, 40, 163-167.

Y. Berredjem, N. Karst, L. Cattin, A. Lakhdar-Toumi, A. Godoy, G. Soto, F. Diaz, M.A. del Valle, M. Morsli, A. Drici, A. Boulmkh, A.H. Gheid, A. Khelil, J.C. Bernède (2008). Plastic photovoltaic cells encapsulation, effect on the open circuit voltage. Dyes and Pigments, 78, 148-156.

J.C. Blakesley and N.C. Greenham (2009). Charge transfert at polymer-electrode interfaces: The effect of energetic disorder and thermal injection on band bending and opencircuit voltage disorder and thermal injection on band bending and open-circuit voltage, J. Appl. Phys., 106, 034507.

C.J. Brabec., J. E. Shaheen, C. Winder, N.S. Sariciftci, P. Denk (2002). Effect of LiFÕmetal electrodes on the performance of plastic solar cells, Appl. Phys. Lett., 80, 1.

S.S. Braun, W.R. Salaneck, M. Fahlman (2009). Energy-level alignment at organic/metal and organic/organic interfaces, Adv. Mater., 21, 1450.

F. Brovelli, B.L. Rivas, J.C. Bernède, M. A. Del Valle, F. R. Diaz (2007). Electrochemical and optical studies of 1,4-diaminoanthraquine for solar cells applications, Polym. Bull., $58,521-527$.

E.L. Bruner, N. Koch, A.R. Span, S.L. Bernasek, A. Kahn, J. Schwartz (2002). Controlling the Work Function of Indium Tin Oxide: Differentiating Dipolar from Local Surface Effects, J. Am. Chem. Soc., 124, 3192-3193. 
R. Cervini, X. C. Li, G. W. C. Spences, A. B. Holmes, S. C. Moratti, R. H. Friend. (1997). Electrochemical and optical studies of PPV derivatives and poly(aromatic oxadiazoles), Synthetic Metals, 84, 359-360.

M.Y. Chan, S.L. Lai, M.K. Fung, C.S. Lee, S.T. Lee, (2007). Doping-induced efficiency enhancement in organic photovoltaic devices, Appl. Phys. Lett., 90, 023504.

J.A. Chaney, S.E. Koh, C.S. Dulcey, P.E. Pehrsson (2003). Surface chemistry of carbon removal from indium tin oxide by base and plasma treatment, with implications on hydroxyl termination, Appl. Surf. Sci., 218, 259-267.

C-H. Chang, S.-A. Chen (2007). Effect of ionization potential change in poly(3,4ethylenedioxythiophene):poly(styrenesulfonic acid) on the performance of polymer light emitting diodes due to its reaction with indium tin oxide, Appl. Phys. Lett., 91, 103514.

F.-C. Chen, J.-L. Wu, C.-L. Lee, Y. Hong, C.-H. Kuo, M.H. Huang, (2009). Plasmonicenhanced polymer photovoltaic devices incorporating solution-processable metal nanoparticles, Appl. Phys. Lett., 95, 013305.

L.L. Chen, W.L. Li, H.Z. Wei, B. Chu, B. Li (2006). Organic ultraviolet photovoltaic diodes based on copper phthalocyanine as an electron acceptor, Sol. Energy Material, 90, 1788-1796.

A.M. Cowley, S. M. Sze (1965). Surface States and Barrier Height of Metal-Semiconductor Systems, J. Appl. Phys., 36, 3212.

X. Crispin. (2004). Interface dipole at organic/metal interfaces and organic solar cells, Solar Energy Materials \& Solar Cells 83, 147-168.

S. Demmig, H. Langhals (1988). Leichtlösliche, lichtechte Perylen-Fluoreszenzfarbstoffe, Chem. Ber., 121, 225-230.

S.H. Demtsu, J.R. Sites (2006). Effect of back-contact barrier on thin-film CdTe solar cells, Thin Solid Films, 510, 320-324.

C. Donley, D. Dunphy, D. Paine, C. Carter, K. Nebesny, P. Lee, D. Alloway, N.R. Amstrong (2002). Characterization of Indium-Tin Oxide Interfaces Using X-ray Photoelectron Spectroscopy and Redox Processes of a Chemisorbed Probe Molecule: Effect of Surface Pretreatment Conditions, Langmuir 18, 450-457.

J. Drechsel, B. Männig, D. Gebeyehu, M. Pfeiffer, K. Leo, H. Hoppe (2004). MIP-type organic solar cells incorporating phthalocyanine/fullerene mixed layers and doped widegap transport layers, Organic electronics 5 175-186.

D. Duche, P. Torchio, L. Escubas, F. Monestier, J.-J. Simon, F. Flory, G. Mathan, (2009). Improving light absorption in organic solar cells by plasmonic contribution, Sol. Energy Mater. Sol. Cells, 93, 1377-1382.

G. East, M. A. del Valle (2000). Easy to make Ag/ AgCl reference electrode, J. Chem. Educ. 77(1) 97.

M. Fahlman, A. Crispin, X. Crispin, S.K.M. Henze, M.P. de Jong, W. Osikowicz, C. Tengstedt, W.R. Salaneck (2007). Electronic structure of hybrid interfaces for polymer-based electronics, J. Phys.: Condens. Matter, 19183202.

Z.R. Hong, Z.H. Huang, X.T. Zeng, (2006). Investigation into effects of electron transporting materials on organic solar cells with copper phthalocyanine/C60 heterojunctions, Chem. Phys. Lett., 425, 62-65.

H. Hoppe, N.S. Sariciftci (2004). Organic solar cells: An overview, J. Mater. Res., 7, 1924-1945.

C.M. Hsu, W.-T. Wu, (2004). Improved characteristics of organic light-emitting devices by surface modification of nickel-doped indium tin oxide anode, Appl. Phys. Lett., 85, 840. 
J. Huang, J. Yu, H. Lin, Y. Jiang (2009). Detailed analysis of bathocuproine layer for organic solar cells based on copper phthalocyanine and C60, J. Appl. Phys., 105, 073105.

H.C. Im, D.C. Choo, T.W. Kim, J.H. Kim, J.H. Seo, Y.K. Seo, Y.K. Kim (2007). Highly efficient organic light-emitting diodes fabricated utilizing nickel-oxide buffer layers between the anodes and the hole transport layers, Thin Solid Films, 515, 5099-5101.

H. Ishii, N. Hayashi, E. Ito, Y. Washizu, L. Sugi, Y. Kimura, M. Niwano, Y. Ouchi, K. Seki (2004). Kelvin probe study of band bending at organic semiconductor/metal interfaces: examination of Fermi level alignment, Phys. Stat. Sol (a) 201 1075_1094.

C. Jain, M. Willander, V. Kumar, (2007). Conducting Organic Materials and Devices, HighDetectivity Polymer Photodetectors with Spectral Response from $300 \mathrm{~nm}$ to 1450 $\mathrm{nm}$ Semiconductors and Semimetals, 81, 1-188.

X-Y. Jiang, Z.-L. Zhang, J. Cao, M.A. Khan, K.-ul-Haq, W.-Q. Zhu (2007). White OLED with high stability and low driving voltage based on a novel buffer layer MoOx, J. Phys. D: Appl. Phys., 40, 5553-5557.

B. Johnev, M. Vogel, K. Fostoropulos, B. Mertesacker, M. Rusu, M.-C. Lux-Steiner, A. Weidinger (2005). Monolayer passivation of the transparent electrode in organic solar cells, Thins Solid Films, 488, 270-273.

B. Kang, L.W. Tan, S.R.P. Silva (2009). Ultraviolet-illuminated fluoropolymer indium-tinoxide buffer layers for improved power conversion in organic photovoltaics, Organic Electronics 10 1178-1181.

K.S. Kang, H.K. Lim, K.J. Han, J. Kim (2008). Durability of PEDOT : PSS-pentacene Schottky diode, J. Phys. D: Appl. Phys., 41, 012003.

N. Karst, J.C. Bernède (2006). On the improvement of the open circuit voltage of plastic solar cells by the presence of a thin aluminium oxide layer at the interface organic aluminium. Physica Status Solidi (a), 203 R70-R72.

M.A. Katkova, V.A. Ilichev, A.N. Konev, M.A. Batenkin, L.L. Pestova, A.G. Vitukhnovsky, Bochkarev M.N. (2008). Modification of anode surface in organic light-emitting diodes by chalcogenes, Appl. Surf. Sciences 254 2216-2219.

S. Kato (2005). Designing Interfaces That Function to Facilitate Charge Injection in Organic Light-Emitting Diodes, J. Am. Chem. Soc., 127 11538-11539.

J.S. Kim, R.H. Friend, F. Cacialli (1999). Surface energy and polarity of treated indium-tinoxide anodes for polymer light-emitting diodes studied by contact-angle measurements, J. Appl. Phys. 86, 2774.

J.Y. Kim, K. Lee, N.E. Coates, D. Moses, T.Q. Nguyen, M. Dante, A.J. Heeger, (2007) Efficient Tandem Polymer Solar Cells Fabricated by All-Solution Processing, Science, 317, 222

J.Y. Kim, S.H. Kim, H.-H. Lee, K. Lee, W. Lee, W. Ma, X. Gong, A.J. Heeger, (2006). New Architecture for High-Efficiency Polymer Photovoltaic Cells Using Solution-Based Titanium Oxide as an Optical Spacer, Adv. Mater., 18 572-576.

N. Kim, W.J. Potscavage Jr., B. Domercq, B. Kippelen, S. Graham, (2009). A hybrid encapsulation method for organic electronics, Appl. Phys. Lett., 94, 163308.

S.-S Kim, S.-I. Na, J. Jo, D.-Y. Kim, Y.-C. Nah, (2008). Plasmon enhanced perfomance of organic solar cells using electrodeposited Ag nanoparticles, Appl. Phys. Lett., 93, 073307.

S.Y. Kim, K. H. Lee, B.D. Chin, J.-W. Yu (2009). Network structure organic photovoltaic devices prepared by electrochemical copolymerization, Solar Energy Materials $\mathcal{E}$ Solar Cells 93, 129-135. 
Y. Kinoshita, T. Hasobe, H. Murata (2007). Control of open-circuit voltage in organic photovoltaic cells by inserting an ultrathin metal-phthalocyanine layer, Appl. Phys. Lett., 91, 083518.

Th. Kugler, W. R. Salaneck, H. Rast, A. B. Holmes (1999). Polymer band alignment at the interface with indium tin oxide: consequences for light emitting devices, Chem. Phys. Lett., 310, 391-386.

B. Kouskoussa, M. Morsli. K. Benchouk, G. Louarn, L. Cattin, A. Khelil, J.C. Bernede, (2009). On the improvement of the anode/organic material interface in organic solar cells by the presence of an ultra-thin gold layer. Physica Status Solidi (a) 206, 311-315.

Th. Kugler, A. Johansson, I. Dalsegg, U. Gelius, W.R. Salanek (1997). Electronic and chemical structure of conjugated polymer surfaces and interfaces: applications in polymerbased light-emitting devices, Synthetic Metals, 91, 143-146.

Th. Kugler, W. R. Salaneck, H. Rast, A. B. Holmes (1999). Polymer band alignment at the interface with indium tin oxide: consequences for light emitting devices, Chem. Phys. Lett. 310, 391-396.

A. Latef, J. C. Bernède (1991). Study of the thin film interface Aluminium -Tellurium, Phys. Stat. Sol. (a), 124, 243.

C.S. Lee, J.X. Tang, Y.C. Zhou, S.T. Lee, Interface dipole et metal-organic interfaces: contribution of metal induced interface states (2009). Appl. Phys. Lett. 94113304.

C.N. Li, C.Y. Kwong, A.B. Djurisic, P.T. Lai, P.C. Chui, W.K. Chan, S.Y. Liu (2005). Improved performance of OLEDs with ITO surface treatments, Thins Solid Films 477 57-62.

Y. Li, Y. Cao, D. Wang, G. Yu, A. S. Heeger (1999). Electrochemical properties of luminescent polymers and polymer light-emitting electrochemical cells, Synthetic Metals, 99, 243248.

S. G. Liu, G. Sui, R. A. Cormier, R. M. Leblanc, B. A. Gregg (2002). Self-Organizing Liquid Crystal Perylene Diimide Thin Films: Spectroscopy, Crystallinity, and Molecular Orientation, J. Phys. Chem. B, 106, 1307-1315.

Lord Kelvin (1898). Philos. Mag., 46, 82.

H-T. Lu, M. Yokoyama (2004). Plasma preparation on indium-tin-oxide anode surface for organic light emitting diodes, Journ. Crys. Growth, 260, 186-190.

D. Lüthi, , M. Le Floch, B. Bereiter, T. Blunier, J.-M. Barnola, U. Siegenthaler, D. Raynaud, J. Jouzel, H. Fischer, K. Kawamura, and T.F. Stocker (2008). High-resolution Carbon dioxide concentration record 650,000-800,000 years before present, Nature. 453 379382.

T. Matsushima, Y. Kinoshita, H. Murata (2007). Formation of Ohmic hole injection by inserting an ultrathin layer of molybdenum trioxide between indium tin oxide and organic hole-transporting layers, Appl. Phys. Lett., 91, 253504.

A.G. Milnes, D.L. Feucht 1972. Heterojunctions and metal semi-conductor junctions. Academic Press Editor, New York,

A.J. Morfa,. K.L. Rowlen, T.H. Reilly III, M.J. Romero, J. van de Lagemaat, (2008). Plasmonenhanced solar energy conversion in organic bulk heterojunction photovoltaics, Appl. Phys. Lett., 92, 013504.

M. Niggemann, M. Riede, A. Gombert, K. Leo (2008). Light trapping in organic solar cells, Phys. Stat. Sol. $(a$,$) 205, 2862-2874.$

T. Nishi, K. Kanai, Y. Ouchi, M.R. Willis, K. Seki (2005). Evidence for the atmospheric $p$-type doping of titanyl phthalocyanine thin film by oxygen observed as the change of interfacial electronic structure, Chem. Phys. Lett., 414, 479-482. 
F. Nüesch, L.J. Rothberg, E.W. Forsythe, Q. Toan Le, Y. Gao, (1999). A photoelectron spectroscopy study on the indium tin oxide treatment by acids and bases, Appl. Phys. Lett., 74, 880.

F. Padinger, R.S. Rittenberger, N.S. Sariciftci (2003). Effects of Postproduction Treatment on Plastic Solar Cells, Adv. Funct. Mater., 13, 85-88.

S. Y. Park, Y. H. Noh, H. H. Lee (2006). Introduction of an interlayer between metal and semiconductor for organic thin-film transistors, Appl. Phys. Lett., 88, 113503.

P. Peumans, V. Bulovic, S.R. Forrest (2000). Efficient photon harvesting at high optical intensities in ultrathin organic double-heterostructure photovoltaic diodes, Appl. Phys. Lett. 76, 2650.

P. Peumans, S.R. Forrest (2001). Very-high-efficiency double-heterostructure copper phthalocyanine $/ C_{60}$ photovoltaic cells, Appl. Phys. Lett. 79, 126-128

M. Pfeiffer, K. Leo, N. Karl (1996). Fermi level determination in organic thin films by the Kelvin probe method, J. Appl. Phys. 80, 6880,

K.L. Purvis, G. Lu, J. Schwartz, S.L. Bernasek (2000). Surface Characterization and Modification of Indium Tin Oxide in Ultrahigh Vacuum, J. Am. Chem. Soc., 122, 1808-1809.

C. Qiu, Z. Xie, H. Chen, M. Wong, H.S. Kwok (2003). Comparative study of metal or oxide capped indium-tin oxide anodes for organic light-emitting diodes, J. Appl. Phys., 93, 3253.

B.P. Rand, D.P. Burk, S.R. Forrest (2007). Offset energies at organic semiconductor heterojunctions and their influence on the open-circuit voltage of thin-film solar cells, Phys. Rev. B 75, 115327,

B.P. Rand, J. Li, J. Xue, R.J. Holmes, M.E. Thompson, S.R. Forrest (2005). Organic doubleheterostructure photovoltaic cells employing thick tris(acetylacto)ruthenium(III) exciton-blocking layers, Adv. Mater., 17, 2714-2718.

C.A. Rozzi, F. Mangi, F. Parmigiani (2003). Ab initio Fermi surface and conduction-band calculations in oxygen-reduced $\mathrm{MoO}_{3}$, Phys. Rev., B 68, 075106.

N.S. Sariciftci, D. Braun, C. Zhang, V. I. Srdanov, A. S. Heeger, G. Stucky, F. Wuld (1993). Semiconducting polymer-buckminsterfullerene heterojunctions: Diodes, photodiodes, and photovoltaic cells, Appl. Phys. Lett., 62, 585.

N. S. Sariciftci, L. Smilowitz, A. J. Heeger, and F. Wudl, (1992). Photoinduced Electron Transfer from a Conducting Polymer to Buckminsterfullerene, Science, 258, 5087, 1474-1476.

J.C. Scott, J.H. Kaufman, P.J. Brock, R. DiPietro, J. Salem, J.A. Goitia (1996). Degradation and failure of MEH-PPV light-emitting diodes, J. Appl. Phys., 79, 2745.

K. Seki, E. Ito, H. Ishii (1997). Energy level alignment at organic/metal interfaces studied by UV photoemission, Synthetic Metals, 91, 137-142,

S.E. Shaheen, C.J. Brabec, N.S. Sariciftci, F. Padinger, T. Fromherz, J.C. Hummelen, (2001). 2.5\% efficient organic plastic solar cells, Appl. Phys. Lett., 78, 841-843.

A. Sharma, P. J. Hotchkiss, S.R. Marder, B. Kippelen, (2009). Tailoring the work function of indium tin oxide electrodes in electrophosphorescent organic light-emitting diodes, J. Appl. Phys., 105, 084507.

S.W. Shi, D.G. Ma, J.B. Peng (2007). Effect of $\mathrm{NaCl}$ buffer layer on the performance of organic light-emitting devices (OLEDs), Eur. Phys. J. Appl. Phys., 40, 141-144.

V.P. Singh, B. Parthasarathy, R.S. Singh, A Aguilera, J. Antony, M. Payne (2006). Characterization of high-photovoltage CuPc-based solar cell structures Solar Energy Materials and Solar Cells, 90, 798-812. 
V.P. Singh, R.S. Singh, B. Parthasarathy, A Aguilera, J. Antony, M. Payne (2005). Copperphthalocyanine-based organic solar cells with high open-circuit voltage, Appl. Phys. Lett., 86, 082106,

Q.L. Song, F.Y. Li, H. Yang, H.R. Wu, X.Z. Wang, W. Zhou, J.M. Zhao, X.M. Ding, C.H. Huang, X.Y. Hou (2005). Small-molecule organic solar cells with improved stability, Chem. Phys. Lett., 416, 42.

P. Sullivan, T.S. Jones, A.J. Ferguson (2007). Structural templating as a route to improved photovoltaic performance in copper phthalocyanine/fullerene $\left(\mathrm{C}_{60}\right)$ heterojunctions, Appl. Phys. Lett., 91, 233114.

S.M. Sze 1981"Physics of Semiconductor Devices" $2^{\text {nd }}$ Edition, John Wiley Editor, New York.

Y. Tanaka, K. Kanai, Y. Ouchi, K. Seki (2009). Role of interfacial dipole layer for energy-level alignment at organic/metal interfaces, Organic Electronics, 10, 990-993.

C.W. Tang (1986). Two-layer organic photovoltaic cell, Appl. Phys. Lett., 48, 183.

C. Tengstedt, W. Osikowioz, W.R. Salaneck, I.D. Parker, C.-H. Hsu, M. Fahlman (2006). Fermi-level pinning at conjugated polymer interfaces, Appl. Phys. Lett., 88, 053502.

B.C Thompson., J.M.J. Fréchet (2008). Polymer-Fullerene Composite Solar Cells, Angew. Chem. Int. Ed., 47, 58-77.

J. Van de Lagemaat, T.M. Barnes, G. Rumbles, S. E. Shaheen, T.J. Coutts, C. Weeks, I. Levitsky, J. Peltola, P. Glatkowski (2006). Organic solar cells with carbon nanotubes replacing $\mathrm{In}_{2} \mathrm{O}_{3}: \mathrm{Sn}$ as the transparent electrode, Appl. Phys. Lett., 88, 233503.

J. Xue, B.P. Rand, S. Uchida, S.R. Forrest, (2005). Mixed donor-acceptor molecular heterojunctions for photovoltaic applications. II. Device performance, J. Appl. Phys., $98,124903$.

I. Yoo, M. Lee, C. Lee, D.-W. Kim, I.S. Moon, D.-H. Hwang (2005). The effect of a buffer layer on the photovoltaic properties of solar cells with P3OT:fullerene composites, Synthetic Metals, 153, 97-100.

H. You, Y. Dai, Z. Zhang, D. Ma (2007). Improved performances of organic light-emitting diodes with metal oxide as anode buffer, J. Appl. Phys., 101, 26105.

X-H. Zhang, B. Domercq, B. Kippelen (2007). High-performance and electrically stable C60 organic field-effect transistors, Appl. Phys. Lett. 91092114.

D. Zhang, Y. Li, Guohui Zhang, Y. Gao, L. Duan, L. Wang, Y. Qiu Lithium cobalt oxide as electron injection material for high performance organic light-emitting diodes (2008). Appl. Phys. Lett., 92, 073301.

Z.Y. Zhong, Y.D. Jiang (2006). Surface treatments of indium-tin oxide substrates for polymer electroluminescent devices, Phys. Stat. Sol., (a), 203, 3882-3892.

Y. Zhou, Y. Wang, W. Wu, H. Wang, l. Han, W. Tian, H. Bässler (2007). Spectrally dependent photocurrent generation in aggregated MEH-PPV:PPDI donor-acceptor blends, Sol. Energy Mat. Solar cells, 91, 1842-1848.

B. Zimmermann, M. Glatthaar, M. Niggermann, M. Riede, A. Hinsch (2005). Electroabsorption studies of organic bulk-heterojunction solar cells, Thin Solid Films, 493, 170-174.

W.A. Zisman. (1932). A new method of measuring contact potential differences in metals, Rev. Sci. Instrum. 3, 367-370. 


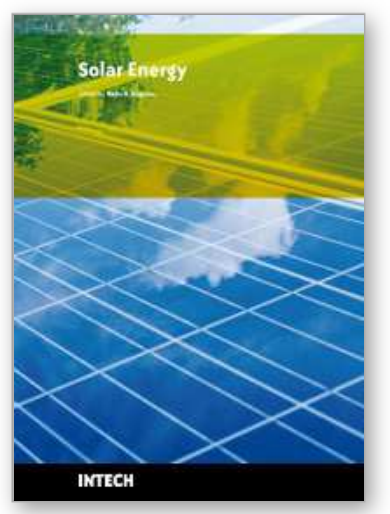

\author{
Solar Energy \\ Edited by Radu D Rugescu
}

ISBN 978-953-307-052-0

Hard cover, 432 pages

Publisher InTech

Published online 01, February, 2010

Published in print edition February, 2010

The present "Solar Energy" science book hopefully opens a series of other first-hand texts in new technologies with practical impact and subsequent interest. They might include the ecological combustion of fossil fuels, space technology in the benefit of local and remote communities, new trends in the development of secure Internet Communications on an interplanetary scale, new breakthroughs in the propulsion technology and others. The editors will be pleased to see that the present book is open to debate and they will wait for the readers' reaction with great interest. Critics and proposals will be equally welcomed.

\title{
How to reference
}

In order to correctly reference this scholarly work, feel free to copy and paste the following:

J. C. Bernède, A. Godoy, L. Cattin, F. R. Diaz, M. Morsli and M. A. del Valle (2010). Organic Solar Cells Performances Improvement Induced by Interface Buffer Layers, Solar Energy, Radu D Rugescu (Ed.), ISBN: 978-953-307-052-0, InTech, Available from: http://www.intechopen.com/books/solar-energy/organic-solarcells-performances-improvement-induced-by-interface-buffer-layers

\section{INTECH}

open science / open minds

\section{InTech Europe}

University Campus STeP Ri

Slavka Krautzeka 83/A

51000 Rijeka, Croatia

Phone: +385 (51) 770447

Fax: +385 (51) 686166

www.intechopen.com

\section{InTech China}

Unit 405, Office Block, Hotel Equatorial Shanghai

No.65, Yan An Road (West), Shanghai, 200040, China

中国上海市延安西路65号上海国际贵都大饭店办公楼405单元

Phone: +86-21-62489820

Fax: +86-21-62489821 
(C) 2010 The Author(s). Licensee IntechOpen. This chapter is distributed under the terms of the Creative Commons Attribution-NonCommercialShareAlike-3.0 License, which permits use, distribution and reproduction for non-commercial purposes, provided the original is properly cited and derivative works building on this content are distributed under the same license. 